\title{
La "era urbana” en debate
}

Neil Brenner. Harvard University, Cambridge, Estados Unidos.

Christian Schmid. Institut Stadt der Gegenwart, Suiza.

RESUMEN | Las observaciones premonitorias sobre las tendencias urbanas del mundo contemporáneo traspasan el discurso académico, político y periodístico de principios del siglo xxi. Entre las más citadas se encuentra la afirmación según la cual vivimos hoy una "era urbana", ya que, por primera vez en la historia de la humanidad, supuestamente más de la mitad de población mundial actual vive en ciudades. En otros contextos discursivos, ideológicos y geográficos, la tesis de la era urbana se ha convertido en una forma de sentido común, doxa alrededor de la cual se articulan preguntas relativas a la condición urbana global contemporánea. En este artículo se sostiene que, a pesar de su larga historia e influencia cada vez más extendida, la tesis de la era urbana es una base errónea para conceptualizar patrones de urbanización mundial: es empíricamente insostenible (un artefacto estadístico) y teóricamente incoherente (una concepción caótica). Esta crítica se enmarca en el contexto de los intentos de posguerra de medir la población urbana del mundo, cuyas principales interrogantes metodológicas y teóricas han permanecido sin resolver en el discurso de la era urbana de principios del siglo XxI. En sus conclusiones, este artículo apunta una serie de perspectivas metodológicas para una comprensión alternativa de la condición urbana global contemporánea.

PALABRas Clave | era urbana, Kingsley Davis, población urbana, transición urbana, urbanización planetaria.

SUMMARY | Foreboding declarations about contemporary urban trends pervade early twenty-first century academic, political and journalistic discourse. Among the most widely recited is the claim that we now live in an 'urban age' because, for the first time in human history, more than half the world's population today purportedly lives within cities. Across otherwise diverse discursive, ideological and locational contexts, the urban age thesis has become a form of doxic common sense around which questions regarding the contemporary global urban condition are framed. This article argues that, despite its long history and its increasingly widespread influence, the urban age thesis is a flawed basis on which to conceptualize world urbanization patterns: it is empirically untenable (a statistical artifact) and theoretically incoherent (a chaotic conception). This critique is framed against the background of postwar attempts to measure the world's urban population, the main methodological and theoretical conundrums of which remain fundamentally unresolved in early twenty-first century urban age discourse. The article concludes by outlining a series of methodological perspectives for an alternative understanding of the contemporary global urban condition

KEYwORDs | urban age, Kingsley Davis, urban population, urban transition, planetary urbanization. 


\section{Introducción}

Las observaciones premonitorias sobre las tendencias urbanas del mundo contemporáneo traspasan el discurso académico, político y periodístico de principios del siglo XXI. Entre las más citadas se encuentra la afirmación según la cual vivimos hoy una "era urbana", ya que, por primera vez en la historia humana, supuestamente más de la mitad de población mundial actual vive en ciudades. En otros contextos discursivos, ideológicos y geográficos, la tesis de la era urbana se ha convertido en una forma de sentido común, doxa alrededor de la cual se enmarcan preguntas relativas a la condición urbana global contemporánea.

A pesar de que intelectuales tan diversos como H. G. Wells, Patrick Geddes y Oswald Spengler han vaticinado la explosión mundial de la urbanización desde comienzos del siglo xx (Madden, 2012), el eminente demógrafo Kingsley Davis (1955) parece haber sido el primer investigador en predecir, con fundamentos estrictamente empíricos, el advenimiento de una transición urbana a escala mundial. Si bien la historiadora urbana Adna Weber (1800) lideró la investigación estadística del crecimiento de la población de la ciudad en diversos contextos nacionales a comienzos del siglo $\mathrm{xx}$, fue recién en 1940 que el tamaño del total de la población urbana mundial se convirtió en un tema para la investigación estable y el debate entre demógrafos, sociólogos e historiadores (K. Davis, 1972). Louis Wirth (1969 [1937], p. 144) comenzó su clásico texto de 1937 sobre urbanismo especulando en torno a este tema, y en las siguientes décadas, Kingsley Davis dedicó parte importante de su carrera a su exploración empírica sistemática (K. Davis, 1945, 1955, 1959, 1965, 1969, 1972). El mismo Davis adoptó un tono rigurosamente científico, pero sus datos, métodos y análisis pronto fueron utilizados como marco para especulaciones relativas a la situación urbana global. En un ejemplo típico, en la edición inaugural de Urban Affairs Quarterly, el arquitecto e investigador en temas de vivienda de las Naciones Unidas, Ernest Weissmann (1965), se basó en los datos demográficos de Davis para anticipar una transición urbana a escala mundial de fin de siècle. Al adoptar un tono apocalíptico, que pronto se volvería de rigor en tales proyecciones, Weissmann sostuvo que más del $60 \%$ de la población mundial sería urbana en el año 2000; que la "crisis urbana en el mundo" resultante requeriría una "tasa de construcción (...) más de 40 veces mayor que la del pasado"; y que a su vez la situación "acarrearía peligros para el progreso humano no menos temibles que la guerra atómica” (Weissmann, 1965, pp. 66, 69; passim).

Equipos pertenecientes a la onu habían estado realizando un seguimiento sistemático de los niveles de población mundial desde 1951 y comenzaron a ofrecer una cobertura mundial de datos a partir de 1968 (K. Davis, 1972, p. 5). Sin embargo, solo en la mitad de la década de 1980 los analistas fueron capaces de anticipar la transición urbana a escala mundial en sus reportes regulares sobre tendencias de asentamiento humano. Una edición de la revista unesco (The Courier) de 1985 sobre "La explosión urbana" articuló una versión temprana de esta declaración:

La universalización del urbanismo es algo nuevo. Antes del año 2000, por primera vez en la historia de la humanidad el mundo tendrá más habitantes de ciudades que habitantes de países (...). Esta evolución demográfica y urbana está ocurriendo 
en el contexto de una crisis económica y el desequilibrio de la distribución de la población estará acompañado por una creciente brecha en la distribución de la riqueza. (Glissant, 1985, pp. 24, 25)

Durante la siguiente década, esta predicción se repitió en los reportes regulares de la ONU sobre Perspectivas de Urbanización Mundial, y para la mitad de la década de 1990 se había vuelto la observación marco en torno a la cual el Centro de la ONu para Asentamientos Humanos (ONU-Habitat) desarrolló su Reporte Global en Asentamientos Humanos (onu-Habitat, 1996, p. xxi). A comienzos de la década del 2000, una serie de estudios de la onu declararon como inminente el comienzo de esta "era urbana"; y en el año 2007, dos agencias principales de la onU organizaron sus reportes anuales en torno a estas dramáticas afirmaciones:

En 2008 el mundo alcanza un hito invisible pero trascendental. Por primera vez en la historia, más de la mitad de la población humana, 3.3 billones de personas, estarán viviendo en áreas urbanas. (United Nations Population Fund [UNFPA], 2007, p. 1)

A veces se necesita solo un ser humano para inclinar la balanza y cambiar el curso de la historia. En el año 2007, ese ser humano se mudará a una ciudad o nacerá en una. Los demógrafos que observan las tendencias urbanas identificarán este momento como el punto de inflexión en que el mundo entró en un nuevo milenio, un período en el que, por primera vez en la historia, la mayoría de la población mundial vivirá en ciudades. (ONU-Habitat, 2007, p. 1)

Desde la mitad de la década del 2000, la tesis de una era urbana también ha ganado considerable prominencia internacional y ha resonado en el trabajo de The Urban Age Project (Proyecto de la Era Urbana), una serie de conferencias e iniciativa investigativa organizada a través de Cities Programme (Programa Cities) en la London School of Economics (LSE), y financiada con una importante donación de la Deutsche Bank's Alfred Herrhausen Society. A la fecha, el proyecto LSE-Deutsche Bank ha producido dos volúmenes gráficamente llamativos y ampliamente distribuidos, The Endless City y Living in the Endless City (Burdett \& Sudjic, 2006, 2010), ambos con referencia directa a las afirmaciones de los demógrafos de la agencia de la ONU. Aunque los volúmenes de LSE-Deutsche Bank contienen una serie de argumentos de fondo y narrativas locales en cuanto a la condición urbana global contemporánea, la tesis dominante relativa a una era urbana es el recurso central en la construcción de su marco de análisis. Según lo explican los editores de los volúmenes:

Dado que más de la mitad de la población mundial vive actualmente en ciudades -un número que es probable que llegue al $75 \%$ en el año 2050 , mientras que representaba solo el $10 \%$ en $1900-(.$.$) los temas urbanos se han vuelto amplia-$ mente globales, con consecuencias significativas para el futuro de nuestro planeta. (Burdett \& Rode, 2006, p. 8)

La tesis de la era urbana también está notablemente representada en las portadas de ambos volúmenes de LSE-Deutsche Bank a través de una serie de números, porcentajes y símbolos que destacan el umbral del $50 \%$ de la población urbana global que -según se afirma- ha sido cruzado recientemente. Estas ilustraciones de la tesis 
de la era urbana sirven como sólidos recursos accesibles y a través de los cuales el proyecto de LSE-Deutsche Bank representa su perspectiva sobre investigaciones y prácticas urbanas globales (figura 1).

\section{FIGURA 1 La era urbana como un recurso de marca}
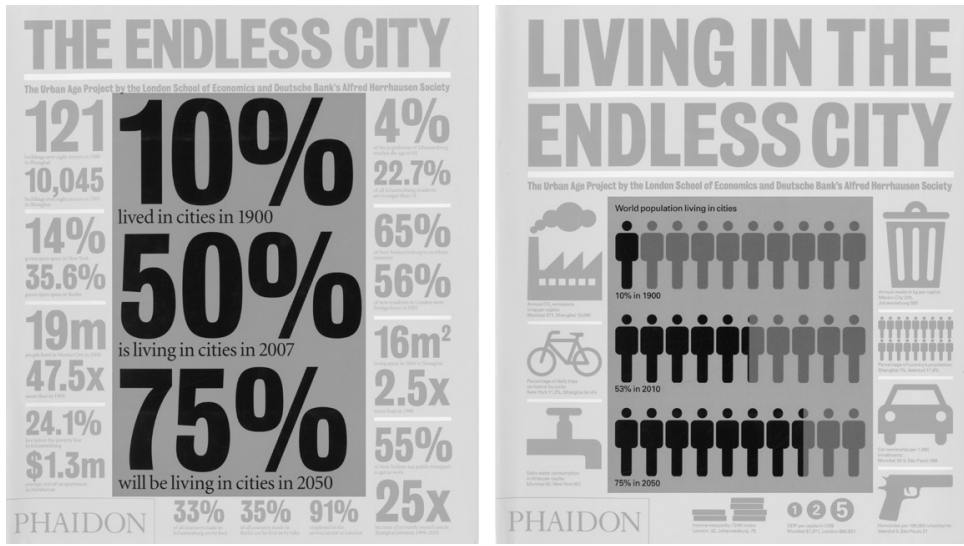

FUENTE BURDETT \& SUDJIC, 2006; 20IO: IMÁGENES DE PORTADA,

(C) PHAIDON PRESS, REPRODUCIDO CON AUTORIZACIÓN

Sin embargo, la tesis de la era urbana no solo incumbe al campo de los demógrafos de la ONU y al equipo de investigación de LSE-Deutsche Bank. Desde finales de la década de 1990 ha sido abordada cada vez con más frecuencia en investigaciones internacionales sobre los estudios y políticas urbanas, a menudo de intelectuales y profesionales influyentes, como una metanarrativa marco para variadas investigaciones sobre ciudades. Es así que, al comienzo de la década del 2000, el equipo de investigación de Harvard, de Rem Koolhaas, abrió su informe Mutations (Mutaciones) con una rendición de una plana de la tesis de la era urbana de la onu (figura 2).

FIGURA 2 La era urbana como metanarrativa marco

At the outset of
the twentieth century
$10 \%$ of the population
lived in cities
In 2000 ,
around $50 \%$ of the
world population
lives in cities

In 2025, the number of city-dwellers could reach 5 billion individuals (two thirds of them in poor countries)

FUENTE KOOLHAAS, 2000: I-2, C ACTAR, REPRODUCIDO CON AUTORIZACIÓN

NOTA TRADUCCIÓN DE LA IMAGEN: AL COMIENZO DEL SIGLO XX, UN IO\% DE LA POBLACIÓN VIVÍA EN CIUDADES. EN ELAÑO 2OOO, ALREDEDOR DEL $50 \%$ DE LA POBLACIÓN MUNDIALVIVE EN CIUDADES. PARA EL 2025, EL NÚMERO DE HABITANTES DE CIUDADES PODRÍA LLEGAR A 5 BILLONES (DOS TERCIOS DE ELLOS EN PAÍSES POBRES) 
De modo similar, Manuel Castells (2002, p. ix) presentó un volumen sobre la desigualdad urbana y acción comunitaria en el mundo en desarrollo, donde sugiere que:

Nuestro planeta azul se está convirtiendo rápidamente en un mundo predominantemente urbano. Probablemente, mientras lees este libro, estaremos cruzando el umbral del 50\% de población urbana que vive en áreas urbanas, desde un 37\% en 1970 (...). Las fuerzas detrás de este proceso de urbanización acelerada parecen ser irreversibles.

Los editores de un número especial de 2008 de la respetada revista Science repiten tal afirmación:

Las ciudades ahora albergan a más 6.6 billones de humanos, lo que representa más de la mitad del mundo. Para 2030, cerca de 5 billones de personas vivirán en ciudades. (Ash, Jasny, Robert, Stone \& Sugden, 2008)

El tropo también es repetido por investigadores que trabajan para la empresa de consultoría McKinsey \& Company, en un informe reciente sobre el rol de la economía en las ciudades:

El mundo está al borde de un cambio de población del campo a la ciudad (...) Por primera vez en la historia, más de la mitad de la población mundial está viviendo en ciudades y urbes. (McKinsey Global Institute, 2011, p. 3)

Incluso el apasionado crítico urbanista Mike Davis abre Planet of Slums (Planeta de ciudades miseria) (2006) con su propia fórmula de la declaración de la ONU:

En algún momento del próximo o los próximos dos años, una mujer dará a luz en el barrio de Lagos de Ajegunle, un joven huirá de su pueblo en el oeste de Java hacia las luces de Yakarta, o un agricultor se mudará con su empobrecida familia a uno de los innumerables pueblos jóvenes de Lima. El evento exacto no es importante y pasará totalmente desapercibido. No obstante, constituirá un punto de inflexión, comparable a la revolución neolítica o industrial. Por primera vez, la población urbana de la Tierra superará en número a la población rural. (p. 1)

Como indican las citas anteriores, la tesis de la era urbana hoy se repite con una regularidad constante en diversos terrenos discursivos, institucionales y políticos, incluyendo a algunos de los intelectuales urbanos más influyentes de nuestro tiempo (Gleeson, 2012). De hecho, se podría agregar un sinnúmero de ejemplos adicionales de este tropo discursivo de aparente omnipresencia a partir de distintas organizaciones internacionales (incluidas las Naciones Unidas, el Banco Mundial y la Organización Mundial de la Salud), informes de investigación de organismos gubernamentales y no gubernamentales, revistas científicas internacionales, revistas y artículos periodísticos, así como documentos de planificación, diseño y consultoría, actas de conferencias y presentaciones públicas de políticos, desarrolladores, arquitectos y urbanistas de todo el mundo. La era urbana, en definitiva, parece haberse convertido en un marco o punto de referencia para casi cualquier persona interesada en justificar la importancia de las ciudades como sitios de investigación, intervención de políticas, práctica de planificación/diseño, inversión o activismo 
comunitario. Al igual que la noción de modernización en la década de 1960 y la de globalización en los años 1980 y 1990, la tesis de una era urbana parece haberse convertido en una metanarrativa omnipresente a la que los lectores tempranos del siglo XXI y las audiencias solo pueden asentir en reconocimiento, encantados con sus elementos básicos.

En este artículo se sostiene que, a pesar de su larga historia en la demografía urbana y su influencia cada vez más extendida en el discurso académico y la política contemporánea, la tesis de la era urbana es una base errónea para conceptualizar los patrones de urbanización del mundo contemporáneo: es empíricamente insostenible (un artefacto estadístico) y teóricamente incoherente (una concepción caótica). Esta crítica se enmarca en el contexto de los intentos de posguerra de medir la población urbana del mundo, cuyas principales interrogantes metodológicas y teóricas han permanecido sin resolver en el discurso de la era urbana de principios del siglo xxi. En sus conclusiones, este artículo señala una serie de perspectivas metodológicas para una comprensión alternativa de la condición urbana global contemporánea.

\section{Antecedentes: el debate de posguerra sobre los umbrales de población urbana}

Desde la década de 1950, cuando se intentó por primera la investigación sistemática de la población urbana mundial, los analistas lucharon contra un problema empírico y teórico fundamental: ¿`ómo determinar los límites espaciales apropiados de las zonas cuyas poblaciones se fueran a medir? Dadas las incesantes dinámicas de la reestructuración socioespacial que han reconfigurado continuamente los límites, escala y morfología de la urbanización desde el siglo XIX, parecería inútil imponer una determinación estadística o analítica sobre cualquier espacio de asentamiento, urbano o de otro tipo, incluso para el cálculo demográfico más básico. Sin embargo, ¿no se necesita tal determinación para medir el tamaño de una población a cualquier escala? Desde los primeros intentos de medición de población urbana del mundo, este polémico asunto ha sido enfrentado a través de diversas estrategias metodológicas, pero nunca se ha resuelto de manera satisfactoria. Existen enfoques demográficos que intentan solucionar este problema fundamentalmente espacial -¿dónde trazar los límites de un territorio urbano/en proceso de urbanización?, ¿convirtiéndolo en un territorio numérico?, ¿cuántos habitantes se requieren, dentro de una unidad jurisdiccional predefinida, para justificar su clasificación como "urbana"?-. Así surgió el debate sobre los umbrales de población urbana (urban population thresholds, UPT, por sus siglas en inglés), que comenzó en la década de 1930 y persiste hasta la actualidad (Schnore, 1964; Bloom, Canning, Fink, Khanna \& Salyer, 2010; Montgomery, 2010).

Kingsley Davis fue uno de los primeros en contribuir a este tipo de debates. En una de sus oposiciones más notorias e influyentes a este desafío, derivado de sus esfuerzos pioneros por construir un Índice Mundial de Recursos Urbanos con sus colegas de la Universidad de Columbia, inicialmente trabajó con una noción bastante imprecisa y contextual de las "ciudades": contar con poblaciones 
sustancialmente mayores que los "poblados" más pequeños y las áreas circundantes en un período histórico dado (K. Davis, 1955; Davis \& Hertz Golden, 1954).

Pese a que Davis sugirió que la UPT variaría históricamente, se aventuró a una definición de "urbanización auténtica" como una situación en la que "una parte sustancial de la población vivía en pueblos y ciudades” (K. Davis, 1955, p. 433). Esta noción fue formalizada como: " $\mathrm{U}=\mathrm{P}_{\mathrm{c}} / \mathrm{P}_{\mathrm{t}}$ " $\left(\mathrm{U}=\right.$ urbanización; $\mathrm{P}_{\mathrm{c}}=$ población de las ciudades; y $\mathrm{P}_{\mathrm{t}}=$ población total); la idea clave era que las tasas de urbanización podían fluctuar "independientemente del número absoluto de personas que vivan en las ciudades”, ya que estaban supeditadas al tamańo absoluto de la población (nacional) (Davis \& Hertz Golden, 1954, p. 7). Sobre esta base, reflexionando en torno al período de modernización capitalista que siguió después de la primera revolución industrial, Davis introdujo lo que es probablemente una de sus maniobras analíticas más conocidas: propuso una definición primaria de ciudad como lugares que albergan una población de 100.000 o más, y otra definición secundaria basada en un umbral menor, de 20.000 habitantes. A raíz de esto, en una incursión en lo que entonces era terreno estadístico inexplorado, él y sus colegas produjeron algunas de las primeras estimaciones de población urbana mundial desde 1800, así como algunas predicciones sobre su evolución. Medio siglo antes de las declaraciones de la era urbana del equipo ONU-Habitat y LSEDeutsche Bank, Davis (1955) proclamó firmemente que "la especie humana se está moviendo rápidamente en la dirección de una existencia casi exclusivamente urbana” (p. 434). Una década más tarde, fue aún más específico en su predicción: “considerando la tasa de 1950-1960, el término "mundo urbanizado" será aplicable mucho antes del final del siglo" (K. Davis, 1965, p. 52; véase también K. Davis, 1972, p. 121).

Pero, ¿por qué un UPT de 100.000 y no uno menor o mayor? Davis no ofreció ninguna justificación teórica para su elección: simplemente demostró lo que tal criterio, así como el de 20.000, implicaría en términos empíricos en las mediciones urbanas en cuestión, tanto a escala mundial como en las principales regiones del mundo (K. Davis, 1955, p. 434, figura 2). Desde finales de la década de 1950 y a lo largo de la década de 1960, junto con sus colegas de la Oficina de Investigación Social Aplicada de Columbia y el Instituto de Estudios Internacionales de Berkeley, Davis intensificó sus esfuerzos para afinar e implementar este esquema con el fin de crear un conjunto de datos cuyas unidades básicas fueran adecuadas para comparaciones entre países. A pesar de varias importantes modificaciones técnicas y empíricas a la fórmula original, la especificidad de dichas unidades fue tratada superficialmente. Su definición fue entendida principalmente como un desafío metodológico -como un "problema de comparabilidad” (Gibbs \& Schnore, 1960, 160) - resultado de la falta de datos internacionales estandarizados y de "los problemas técnicos surgidos a partir de esta deficiencia" (K. Davis, 1959, pp. 1-2).

Y, sin embargo, aun cuando los cálculos estadísticos de Davis parecían ratificar la condición urbana basada en un UPT relativamente arbitrario, eventualmente articuló una comprensión más matizada de las transformaciones histórico-geográficas que se desarrollaban a su alrededor. Así, concluyó uno de sus primeros estudios 
insistiendo en que "hay que evitar asumir que las ciudades conservarán su forma actual” (K. Davis, 1955, p. 437). En un pasaje especulativo pero predictivo que apuntaba más allá de los confines de un enfoque puramente demográfico, Davis describió brevemente los drásticos procesos de la expansión y dispersión metropolitana que ya estaban alterando profundamente las configuraciones urbanas y regionales heredadas durante el primer período de la posguerra, sobre el cual estaba escribiendo. Para esto, consideró la posibilidad de que la "ruralidad" podría desaparecer por completo en relación con la consolidación de un "nuevo tipo de existencia urbana": "en la periferia, es muy posible que la metrópolis y el campo, mientras una se expande y el otro se reduce, se fundan hasta que los límites de una conurbación en expansión choque con los de otra, sin intervenir el área del campo" (K. Davis, 1955, p. 437). En escritos posteriores, Davis reiteró este reconocimiento, con referencia a la intensificación del "desarrollo de la suburbanización y la periferia" en las "sociedades avanzadas", que a su parecer causaba "que todo el proceso de urbanización se volviera ambiguo” (K. Davis, 1965, p. 44). Pese a tal afirmación, les dejó a otros la tarea de reconciliar estas ideas y predicciones con sus propias estimaciones estadísticas, mucho más influyentes, cuya coherencia dependía de una comprensión extremadamente circunscrita, si no estática, del espacio de los asentamientos humanos.

La esencia espacial de la conceptualización de Davis fue captada concisamente en un mapa producido por la División de Asuntos Económicos y Sociales de la ONU, uno de varios mapas producidos por prominentes científicos sociales urbanos durante este tiempo (por ejemplo, Hoyt, 1966 [1962], p. 329; Berry 1961, p. 580, figura 1), que se basó en gran medida en los datos y métodos de Davis (United Nations Department of Economic and Social Affairs [UN-DESA - Departamento de Asuntos Económicos y Sociales de las Naciones Unidas], 1969). El mapa, no obstante, insertado dentro de un texto que enfatizaba en repetidas ocasiones las limitaciones de los existentes datos urbanos de las Naciones Unidas a la luz de los problemas de comparabilidad, así como la dinámica en curso de reestructuración socioespacial y sociodemográfica, representaba el estado del conocimientos sobre la urbanización mundial mediante la adopción de un UPT uniforme de 20.000 para todos los conjuntos de datos nacionales. Las masas de tierra continentales y subcontinentales fueron codificadas de acuerdo con los niveles nacionales de urbanización según lo registrado en 1960 (figura 3). 


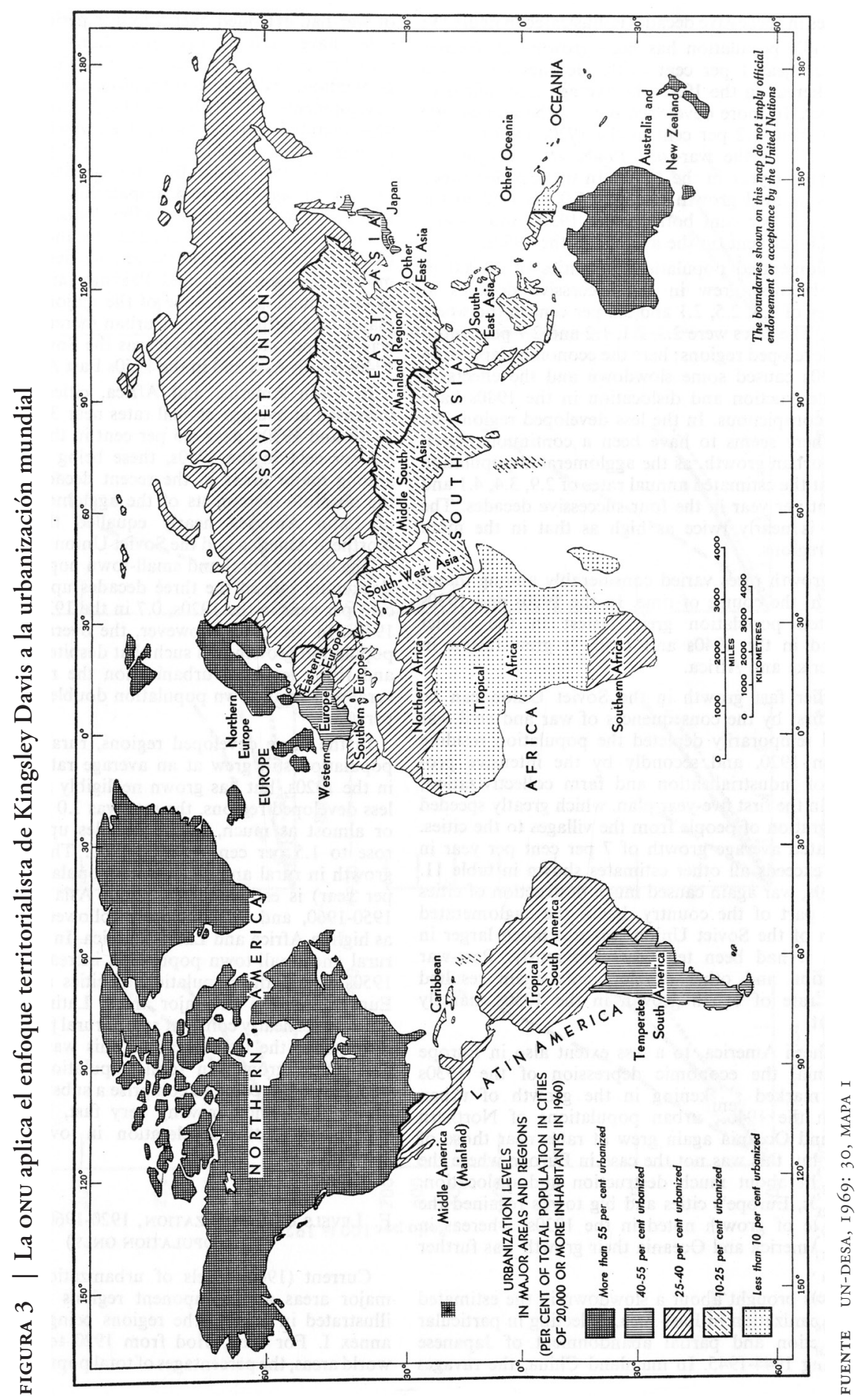


Desde un punto de vista contemporáneo, hay tres aspectos claves de esta representación de urbanización mundial que son especialmente llamativos. En primer lugar, el mapa no intenta representar áreas urbanas o rurales, o incluso grandes ciudades. $\mathrm{Si}$ bien para los investigadores de la onu la brecha urbano/rural era un hecho cuantitativo, demostrable a través de datos demográficos duros, consideraban que el proceso de demarcación de sus límites espaciales precisos, ya fuera dentro de o entre Estados o continentes, era irrelevante. Como consecuencia, la mayor parte del mapa mundial está vacío: las únicas líneas de demarcación son las fronteras nacionales, divisiones subcontinentales y masas de tierra continental. En segundo lugar, el mapa articula una visión de la urbanización en la que los territorios nacionales y los continentes y subcontinentes son vistos como escalas naturales de la urbanización a través de una técnica de agregación. De esta manera, los investigadores de la ONU espacializaron la conceptualización de Davis de tasas de urbanización como una medida proporcional (crecimiento de la población de la ciudad como una proporción del crecimiento de la población nacional). Dentro de este marco, las ubicaciones geográficas y los límites espaciales de las ciudades y regiones metropolitanas dejaron de tener relevancia; lo que importaba era sus tamaños de población diferencial en relación con los de las unidades más grandes (territorios nacionales, subcontinentes, continentes). En tercer lugar, aunque el mapa representa los niveles de urbanización como una propiedad que abarca los territorios de gran escala, sus autores reconocieron que los fenómenos "urbanos" contenidos dentro de estos últimos eran, en la práctica, bastante heterogéneos, incluso en términos puramente demográficos. Las diferencias entre las ciudades cuya población superaba el UPT especificado de 20.000 no fueron recogidas en el mapa; tampoco había similitudes entre estas localidades supuestamente urbanas y los asentamientos que, debido a sus bajos niveles de población, fueron clasificados como no urbanos o rurales. De esta manera, la misión de codificar territorios completos de acuerdo con niveles agregados de urbanización ha supuesto una dramática simplificación estadística y cartográfica de los patrones de facto de diferenciación socioespacial interna. Sin embargo, el equipo de investigación del Departamento de Asuntos Económicos y Sociales de la onU consideró apropiada esta representación homogeneizadora de los territorios nacionales, subcontinentales o continentales, dada la necesidad de comprender los patrones diferenciales de urbanización a escala mundial. Mientras que las metanarrativas contemporáneas de la era urbana se basan en datos actualizados, a continuación se argumenta que han reproducido en forma casi idéntica las orientaciones conceptuales subyacentes, los imaginarios geográficos y estrategias de representación asociados con este modelo metodológicamente territorialista de la urbanización mundial de la década de 1960 .

\section{El imperativo teórico: las críticas de posguerra de la demografía urbana}

En contraste con la forma en que Kingsley Davis confronta empírica y metodológicamente el problema de la definición de la unidad (de población) urbana, Louis Wirth (1969 [1937]) había insistido en su carácter fundamentalmente teórico casi dos décadas antes. Incluso en ese momento, las definiciones de ciudades basadas en la población habían alcanzado tal prominencia entre los historiadores urbanos, 
sociólogos y demógrafos, que Wirth quiso abrir su gran declaración teórica sobre urbanismo con un ataque frontal contra ellos. En términos empíricos generales, Wirth reconoció la necesidad práctica de tales definiciones, pero a nivel teórico las consideraba ahistóricas e indeterminadas. Si el UPT relevante se hubiera fijado en 2.500, $4.000,8.000,10.000,25.000$ o 100.000 , Wirth sostenía, una definición puramente basada en la población de la condición urbana era "obviamente arbitraria", ya que "no existe una definición de urbanismo que pueda aspirar a ser satisfactoria si los números son el único criterio" (Wirth, 1969 [1937], p. 145). En la medida en que las definiciones UPT siempre dependían de los límites de las unidades administrativas locales y regionales existentes, debían ser consideradas como artefactos de convención jurídica en lugar de como indicadores de circunstancias sociológicamente significativas.

Por otra parte, sostenía Wirth, dado el constante flujo de personas por dichos límites, las definiciones basadas en la población de las áreas urbanas proporcionaban una indicación de urbanidad aproximada y a menudo sumamente engañosa. Las unidades de asentamientos ostensiblemente "no urbanos", ubicadas en la periferia de los centros metropolitanos, a menudo tenían más en común con las áreas rurales que con las grandes ciudades situadas en las regiones más aisladas. Wirth, por lo tanto, desestimó secamente el supuesto de los demógrafos según el cual "los atributos urbanos repentinamente dejaron de manifestarse más allá de una línea límite arbitraria” (Wirth, 1969 [1937], p. 146). En una fórmula que recuerda sorprendentemente la caracterización de Marx y Engels (2000 [1848], pp. 248-249) de la economía mundial capitalista en el Manifiesto Comunista, en el mismo texto Wirth insistía en que la condición urbana del siglo xx debía entenderse con referencia a las redes de condensación de la conectividad entre constelaciones dispersas, diferenciadas, en expansión e inestables de la organización social metropolitana, y cada vez más con referencia a un horizonte emergente en todo el mundo hacia el que los procesos de urbanización se estaban extendiendo:

El grado en que el mundo de hoy puede decirse "urbano" no se mide con precisión o completamente por la proporción de la población total que vive en las ciudades. Las influencias que las ciudades ejercen sobre la vida social del hombre son mayores que lo que indicaría la proporción de población urbana, dado que la ciudad es (...) el centro de inicio y control de la vida económica, política y cultural que ha llevado a la mayoría de las partes remotas del mundo a su órbita y ha entrelazado diversas áreas, pueblos y actividades en un cosmos. (pp. 143-144)

Sin embargo, a pesar de reconocer Wirth las dimensiones límite-expansivas de la urbanización, su teoría del urbanismo estaba casi completamente aislada de estos puntos de vista, y del terreno analítico y empírico en gran medida desconocido que se abría con ellos (Brenner, 2012). Su teoría se basó, en cambio, en la suposición de que la vida social seguía estando -de hecho, necesariamente está- organizada en sobres espaciales delimitados coherentemente ("asentamientos humanos") que podrían ser clasificados perfectamente, y cuyas propiedades demográficas (incluyendo la tríada clásica de tamańo, densidad y heterogeneidad) engendraban formas distintivas de comportamiento social dentro de esos límites. En otras palabras, aunque los UPT no se pudieron usar para clasificar la unidad espacial en cuestión, 
Wirth presupuso que esta unidad estaría caracterizada naturalmente por ciertas propiedades socioespaciales, de separación, coherencia y limitación. Es este elemento de la teoría de Wirth el que ha sido canonizado en la sociología urbana del siglo xx, pero veremos que su crítica a la demografía urbana y, de modo más general, su insistencia en el carácter fundamentalmente teórico de lo urbano, son mucho más relevantes para el discurso contemporáneo sobre la condición urbana mundial.

Las intervenciones marxistas del joven Manuel Castells (1977 [1972]) en la década de 1970 resuenan de manera inesperada con la crítica anterior de Wirth sobre la demografía urbana. A pesar de que caracterizó despectivamente la teoría del urbanismo de Wirth como un recuento culturalista de difusión espacial intranacional, Castells abrió The Urban Question con una fuerte crítica a la demografía urbana, esencialmente idéntica a la que el sociólogo de la Escuela de Chicago había presentado cuatro décadas antes. Al medir los distintos UPT adoptados por investigadores urbanos anteriores, así como por la Oficina del Censo de Estados Unidos y la Conferencia Europea de Estadística, Castells (1977 [1972], p. 10) los rechazó abiertamente como expresiones de "empirismo estadístico". Al igual que Wirth, Castells puso en duda la fiabilidad de los "criterios de práctica administrativa" para fines de análisis, ya que no podían capturar adecuadamente "la aceleración del ritmo de urbanización en todo el mundo" (pp. 11, 15). A pesar de sus agudos desacuerdos con Wirth, Castells (1977, pp. 101-112) insistió en que la única delimitación viable de la unidad urbana tendría que ocurrir en el campo teórico. Debido a la "casi total falta de correspondencia entre las fronteras políticas [y jurídicas] y la especificidad de su contenido social" (p. 235), así como el constante cambio y la escala de los procesos de urbanización en el capitalismo moderno, Castells, sin saberlo, se mostró de acuerdo con Wirth en que las definiciones puramente empíricas y territoriales de lo urbano, incluyendo aquellas asociados con UPT, quedarían condenadas a la arbitrariedad, la incoherencia y la obsolescencia casi inmediata. Mientras que la influencia de la solución teórica propuesta por el joven Castells a este problema ha disminuido desde entonces, su énfasis en el carácter intrínsecamente teórico de lo urbano es, al igual que la de su antiguo antagonista sociológico, Wirth, un punto de referencia analítico altamente relevante para los estudios urbanos contemporáneos, especialmente en relación con la tesis de la era urbana.

Los agudos apelativos de Wirth de 1930, reproducidos por Castells en la década de 1970, contra el uso de los UpT en el estudio de la urbanización-arbitrarios, empiristas, ahistóricos - se aplican con sorprendente exactitud a las versiones contemporáneas de la tesis de la era urbana. En esa línea, a continuación sometemos el discurso de la era urbana de comienzos del siglo xxi a una crítica contemporánea. Esta crítica está pensada para aplicarse a la amplia constelación de referencias, discursos, metanarrativas y proyectos de la era urbana que fueron evaluados al inicio de este artículo. Sin embargo, debido a que la recopilación de datos urbanos de la onu sigue siendo tratada por los "usuarios finales (...) como si fuera la verdad absoluta" (Cohen, 2004, p. 25) y sigue siendo la referencia bibliográfica imperativa para las declaraciones contemporáneas de una era urbana, se le presta especial atención aquí. ${ }^{1}$

1 La onu ha seguido un proceso regular de actualización de sus datos y, en menor medida, de sus métodos de recopilación de estos de distintas maneras desde final de la década de 1960 (véase 


\section{La era urbana como un artefacto estadístico}

Antes de retomar las críticas teóricas de la demografía urbana desarrolladas por Wirth y Castells, algunos de los principales problemas empíricos con la tesis de la era urbana requieren atención. El principal de estos es el continuo desacuerdo sobre lo que hay que medir en el análisis de la urbanización mundial, y en qué escala espacial hacerlo. En los contextos nacionales, incluyendo los conjuntos de datos de la onU, no existe una definición estandarizada de la unidad urbana para medir el tamaño de la población base, densidad u otros indicadores de los niveles de urbanización propuestos.

En efecto, los mismos problemas de compatibilidad de datos y demarcación de límites que irritaban a Kingsley Davis y sus colegas en los años 1950 y 1960 permanecen sin ser resueltos en los conjuntos de datos urbanos reunidos regularmente por la División de Población de las Naciones Unidas desde la década de 1970 hasta la revisión más reciente de World Urbanization Prospects en 2011 (United Nations Department of Economic and Social Affairs, Population Division [UN-DESA-PD], 2012).

El problema ha sido discutido extensamente entre los demógrafos y estadistas de la ONU desde 1950, y ha llevado a las organizaciones a emitir y actualizar regularmente sus directrices generales de acuerdo con los medios apropiados para delinear localidades (para una descripción detallada, consultar Champion, 2004). No obstante, en reiteradas ocasiones los investigadores de la onu han concluido que las oficinas nacionales de estadística están en mejor posición para determinar cómo se debe delimitar el "límite urbano/rural". La continua dependencia de la onu respecto de este tipo de estadísticas para sus análisis urbanos supuestamente globales es poco sorprendente, ya que, como lo nota Peter J. Taylor (2002), “La recopilación de datos a gran escala sobre las actividades humanas tiene su origen en las necesidades del Estado y sigue estando dominada por los Estados" (p. 1). En la medida en que la onu ha propuesto una solución técnica a este enigma, sus recomendaciones resuenan de cerca con aquellas introducidas por Kingsley Davis en la fase madura de su trabajo sobre el tema a finales

\footnotetext{
Champion, 2004). La recopilación más reciente de datos urbanos de la onU está disponible en la revisión de 2011 de su serie World Urbanization Prospects (UN-DESA-PD, 2012); y la versión online del reporte entrega archivos de datos en bruto, junto con una variedad de mapas y gráficos basados en lo anterior. Si bien esta discusión somete a diversos aspectos clave del enfoque de la ONU a severas críticas, se debe reconocer que el compromiso a largo plazo de la organización en pos de la recopilación de datos urbanos a nivel mundial ha significado un valioso punto de partida para los análisis de patrones de urbanización planetaria. A pesar de los problemas discutidos a continuación, la versión más reciente de World Urbanization Prospects incluye datos útiles sobre las distribuciones de tamańos de ciudad y niveles de población en las ciudades de algunas de las regiones metropolitanas más grandes del mundo desde la década de 1970. Sostenemos que el desafío es concebir nuevos métodos de recopilación de datos y análisis que iluminen de manera más efectiva la trayectoria a largo plazo de la reestructuración socioespacial del capitalismo. Hacer frente a este desafío implica una tarea significativa de (re)conceptualización en relación con la naturaleza fundamental de la urbanización misma (Brenner \& Schmid, 2011; Brenner, 2013; Schmid, 2012, 2006; Diener, Herzog, Meili, De Meuron \& Schmid, 2006; Lefebvre, 2003 [1970]). En la medida en que los autores y organizaciones relevantes se apropien de los datos y análisis de la ONU sin un sentido crítico, como si estos ofrecieran una ventana sin mediación a "hechos en bruto" de la condición urbana global, se oscurece la necesidad de esta tarea de reconceptualización.
} 
de 1960 en Berkeley; específicamente, con la combinación de indicadores de tamaño de población con otros indicadores auxiliares relacionados con densidad, estructura de mercado de trabajo y gastos de infraestructura. ${ }^{2}$ Pero incluso si fueran aplicadas sistemáticamente, dichas estrategias aún dependerían de los datos decididos a escala de unidades administrativas del Estado (subnacional), solo que combinadas con el fin de dar cuenta de los patrones de facto de aglomeración y uso del suelo dentro de las unidades jurídicas adyacentes. En la práctica, sin embargo, incluso estas modestas propuestas para mejorar la compatibilidad de datos nacionales han demostrado ser imposibles de aplicar, debido a la persistencia de prácticas específicas en los censos a nivel nacional y la continua dependencia de la onU respecto de dichos datos, reunidos por el Estado, para el análisis de la urbanización. En consecuencia, como Champion (2004) concluye, "en resumidas cuentas, la principal fuente mundial de estadísticas comparativas internacionales publicadas sobre población urbana -las Naciones Unidas- sigue utilizando esencialmente la misma óptica de hace medio siglo" (p. 41).

Esta antigua óptica ha generado una visión extremadamente borrosa de la condición urbana global. En particular, los criterios totalmente divergentes en la definición de lo urbano utilizados por oficinas de censo nacionales - ya sea administrativos, basados en la población u otros- han alterado profundamente las estimaciones de población urbana mundial de las Naciones Unidas. La evidencia de estos problemas se puede encontrar en las tablas de datos e informes analíticos propios de la onU, y también han sido ampliamente examinados por demógrafos clave (Bocquier, 2004; Champion, 2004; Cohen, 2004; Satterthwaite, 2007, 2010; Montgomery, 2010; Champion \& Hugo, 2004). A partir de la revisión de 2001 de World Urbanization Prospects (UN-DESA-PD, 2002), 109 países miembros de la ONU (38\%) utilizaron criterios administrativos como base única o principal de sus definiciones urbanas. Esto significó que algunos municipios o localidades fueron declarados urbanos, independientemente del tamaño de la población u otros indicadores, mientras que otras localidades de mayor tamańo y densidad poblacional se excluyeron mediante una resolución administrativa. Esto también llevó a que importantes grupos de población ubicados en las franjas periurbanas de grandes asentamientos metropolitanos, pero posicionados fuera de las fronteras administrativas oficiales de la ciudad, a menudo se clasificaran como "no urbanos". En la misma muestra de datos, el tamaño de la población fue utilizado como el único o principal criterio para 98 clasificaciones urbanas nacionales (34\%); pero los UPT variaron cuantiosamente en los contextos nacionales, desde 100 en Uganda, 200 en Islandia y Suecia, o 400 en Albania y hasta 2000 en Angola y Cuba, 5000 en Botswana y Zambia, y 10.000 en Benin e Italia (Bloom et al., 2010, pp. 22-23; Brockerhoff, 2000, p. 6; Cohen, 2004, p. 26; Uchida \& Nelson, 2010, p. 41). ${ }^{3}$

2 Al final de la década de 1960, investigadores de la División de Población de la onu parecieron haberse apropiado directamente de nuevas técnicas de medición en desarrollo en el laboratorio de investigación de Davis en ese momento. En una escueta nota al final del libro que recopilaba décadas de investigación, Davis (K. Davis, 1972, p. 6, nota 6) indica esto, sugiriendo que los estadistas de la ONU habían adoptado las innovaciones metodológicas de su equipo de investigación de Berkeley, sin atribuírselas, luego de diversas visitas de funcionarios de alto rango de la ONU a su laboratorio.

3 El 28\% restante de los países usó criterios económicos, otros criterios, o no lograron enumerar sus bases de clasificación (Bloom et al., 2010, p. 23; Champion, 2004, pp. 34-35). 
Estos problemas se han intensificado aún más en la medida en que muchos países cambian frecuentemente sus clasificaciones urbanas oficiales, ya sea con referencia a las fronteras individuales de las ciudades o a tipologías de asentamiento más generales. Tales reajustes de definición pueden producir fluctuaciones dramáticas en los niveles de población urbana nacional y mundial -en países muy poblados como China, India, Brasil o Nigeria-, debidas enteramente a modificaciones de clasificación. Un problema igualmente grave se relaciona con el tiempo de recolección de los datos del censo, que varía considerablemente entre los Estados nacionales. En consecuencia, los datos de población utilizados en los análisis urbanos de la onu a menudo provienen de años diferentes. Como mínimo, el 38\% de los datos utilizados en Urbanization Prospects de 2001 de la onU tenían más de ocho años de antigüedad (esta cifra era de un $56 \%$ para los países africanos); el $43 \%$ de los datos urbanos globales tenía entre tres y ocho años de antigüedad (Cohen, 2004, p. 27). El uso de tales indicadores y esquemas clasificatorios variados ha generado resultados estadísticos contradictorios. En un panorama detallado, Satterthwaite (2010) enumera varios ejemplos típicos:

\begin{abstract}
México podría considerarse un $74 \%$ o $67 \%$ urbano en el año 2000 , dependiendo de si los centros urbanos son asentamientos con 2.500 habitantes o más, o asentamientos con 15.000 habitantes o más. El nivel de urbanización de China en 1999 podría haber sido de un 24\%, 31\% o $73 \%$, dependiendo de cuál de las tres definiciones oficiales de poblaciones urbanas hubiera sido utilizada (...). [E]n 1996, el 18\% de la población egipcia vivía en asentamientos de entre 10.000 y 20.000 habitantes, con muchas características urbanas, incluidas una economía no agrícola importante y estructuras ocupacionales. Estas poblaciones no fueron clasificadas como urbanas, a pesar de que sí lo habrían sido en la mayoría de las otras naciones. De considerarse urbanas, esto habría significado que Egipto era mucho más urbanizado, provocando cambios importantes en las tasas de crecimiento urbano. (pp. 84, 85)
\end{abstract}

El caso de India incorpora una nueva arista a la confusión: su oficina nacional de censo se niega a clasificar como urbanas a numerosas ciudades pequeńas y medianas con poblaciones superiores a 5.000 habitantes; en caso de que esto se hiciera, la población urbana del país instantáneamente superaría el umbral legendario del 50\% (Satterthwaite, 2010, p. 84). Se podrían enumerar muchos otros ejemplos, pero el problema básico es evidente: "[L]as unidades en que se expresan las poblaciones urbanas pueden variar en todas las dimensiones relevantes: entre países, dentro de países y durante el tiempo para una ciudad determinada” (Montgomery \& Balk, 2011, p. 93). En consecuencia, "la escala de la población urbana del mundo está fuertemente influenciada por los criterios urbanos utilizados en las naciones con mayor población” (Satterthwaite, 2010, p. 85).

Teniendo en cuenta estos problemas sistémicos de la comparabilidad de los datos dentro de las estadísticas de la ONU, ¿̨hay algún contenido empírico rescatable para la noción de una era urbana? Claramente, las poblaciones están creciendo y cambiando en todo el mundo; su distribución en el paisaje socioespacial es reorganizada constantemente, como también su morfología territorial y la composición demográfica de las unidades político-administrativas en todo el sistema interestatal mundial. Por lo tanto, incluso aunque sus límites y ritmos sean difíciles de medir, 
¿se podría desarrollar una transición urbana mundial, indicando algún cambio cualitativo en el "modo de vida" experimentado por la mayoría de las personas en el planeta? O bien, ¿la famosa predicción de la onu de que se ha cruzado el umbral urbano global del $50 \%$ es simplemente un artefacto de procedimientos estadísticos inadecuados que asimilan las condiciones fundamentalmente heterogéneas bajo un esquema clasificatorio burdamente simplista?

Desde un punto de vista estrictamente empírico, hay dos estrategias principales para hacer frente a estas preguntas. La primera consiste en reconocer los límites de las técnicas de recolección de datos de las Naciones Unidas, dejando de lado la noción de un UPT rígido de 50\%, y proponer una trayectoria para una reorganización socioespacial de lo rural a lo urbano en la mayoría de los Estados en el sistema mundial, proporcionando, así, evidencia de una transición a escala mundial en desarrollo. Satterthwaite (2010) sugiere la siguiente solución:

[E]l nivel mundial de urbanización se entendería mejor como un porcentaje entre 45 y 55, dependiendo de los criterios utilizados para definir las áreas urbanas, en vez de como una cifra precisa ( $50 \%$ en 2008). Es posible que la transición de más de la mitad de la población de áreas urbanas del mundo en realidad haya ocurrido hace unos ańos, con un reconocimiento tardío por parte de gobiernos que clasificaron deliberadamente sus pequeños centros urbanos como rurales. (p. 85)

En este enfoque, la noción de una transición rural-urbana a nivel mundial se conserva intacta, pero se considera que sus expresiones socioespaciales y temporales son más fluidas que en los análisis oficiales de la ONU -se entiende, en efecto, como una tendencia secular a largo plazo y a escala mundial, más que como una transformación coyuntural-. Sin embargo, al igual que en la documentación de las Naciones Unidas, la distinción urbano/rural y la noción de una "unidad" urbana separada se mantienen. La modificación principal consiste en un mayor nivel de reflexión y flexibilidad en la interpretación de las formas heterogéneas de los datos incorporados bajo el postulado de la era urbana.

Una segunda estrategia, potencialmente más radical, implica abandonar el enfoque de la ONu para la recopilación de datos, con su dependencia en fuentes centradas en el Estado, y elaborar nuevos enfoques espacialmente desglosados sobre la base de técnicas de detección remota (Potere \& Schneider, 2007; Potere, Schneider, Angel \& Civco, 2009; Montgomery \& Balk, 2011). Tales fuentes de datos basadas en satélites se han estado desarrollando desde principios de 1990, y actualmente están siendo activadas con mayor sofisticación técnica en varios laboratorios estadounidenses y europeos, institutos de investigación y universidades, incluyendo el Earth Institute de la Universidad de Columbia, el Oak Ridge National Lab y la Agencia Europea del Medio Ambiente. Las principales iniciativas en este sentido incluyen, entre otros, la generación de datos satelitales de luminosidad nocturna, de la Administración Oceánica y Atmosférica Nacional (NOAA, por sus siglas en inglés) y otras agencias gubernamentales, el desarrollo de nuevas formas de datos georreferenciados de población (el Proyecto de Mapeo Rural-Urbano Global [GRump, por sus siglas en inglés], el Cuadriculado de la Población Mundial [GPw, por sus siglas en inglés], la Base de Datos de Población Mundial Landscan), y la elaboración de conjuntos de datos 
georreferenciados de cobertura global de suelo (por ejemplo, CORINE Land Cover y MODis Urban Land Cover). El mayor atractivo de estos enfoques es que permiten la investigación de los patrones de aglomeración en constante cambio, la distribución de la población, la cobertura y uso del suelo, todo lo cual ya no se basa completamente en los datos del censo nacional. La nueva gama de posibilidades de mapeo que nace de esas técnicas está complicando de forma productiva la representación de los procesos de urbanización planetaria (Angel, 2011; Potere \& Schneider, 2007).

Si los recientes desarrollos de detección remota podrían facilitar interpretaciones teóricamente innovadoras de la condición urbana global, es una pregunta que requiere una exploración más profunda (Brenner \& Katsikis, 2013). Lo que compete a esta investigación no es tanto evaluar la viabilidad empírica de las dos estrategias mencionadas anteriormente, sino más bien sugerir que ambas deben ser sometidas a las mismas normas de reflexión teórica sobre las que Wirth y Castells habían insistido tan firmemente en sus evaluaciones críticas de la corriente principal de demografía urbana del siglo xx. Desde este punto de vista, las limitaciones de la tesis de la era urbana contemporánea no pueden ser superadas eficazmente solo por medio de maniobras empíricas, ya sea a través reinterpretaciones creativas de datos basados en el censo de la ONU o por medio de la construcción de las mapeos georreferenciados de indicadores clave, como densidad poblacional, cobertura del suelo o patrones de luminosidad nocturna. Al igual que Wirth y Castells, sostenemos que en cualquier enfoque de investigación urbana basado puramente en datos, un problema teórico irresoluble se oculta "detrás evidencias falsas" (Castells, 1977 [1972], p. 234); más específicamente, la importancia cualitativa de la calificación de "urbana" como una base analítica para la delimitación e interpretación de transformaciones socioespaciales. Ante la falta de reflexividad teórica con respecto a esta fundamental pregunta, incluso las formas más sofisticadas de datos urbanos, georreferenciados u otros, no representan más que cúmulos de información incipiente; tal es el caso de las primeras formas de "empirismo estadístico" del siglo xxi que Castells (1977 [1972], p. 10) había decretado tan intensamente hace cuatro décadas.

\section{La era urbana como concepción caótica}

Si la estructura empírica de la tesis de la era urbana es inestable, entonces sus fundamentos teóricos están obsoletos, habiendo sido erosionados a través del dramático desarrollo y reorganización geográficos del proceso de urbanización que la tesis afirma estar documentando. El problema básico es la fluidez socioespacial de facto y el dinamismo incesante del fenómeno urbano en el capitalismo moderno: su tendencia endémica a explotar morfologías heredadas del urbanismo en todas las escalas espaciales, para crear nuevas formaciones a otra escala de organización territorial urbanizada; y, como Wirth (1969 [1937], pp. 143-144) anticipadamente reconoció, para promover la "urbanización del mundo" mediante la intensificación de independencias socioespaciales en lugares, territorios y escalas. Actualmente, el desigual tejido urbano resultante (Lefebvre, 2003 [1970]) está asumiendo formas policéntricas extremadamente complejas, que ya no se aproximan ni remotamente a los anillos concéntricos y gradientes de densidad lineal asociados con la ciudad 
industrial relativamente delimitada del siglo XIX, las formas metropolitanas de desarrollo urbano que se consolidaron durante las primeras décadas del siglo xx o, para el caso, los sistemas urbanos tendencialmente nacionalizados, que se concretaron en todos los países del norte bajo el capitalismo fordista-keynesiano (Soja \& Kanai, 2007; Soja, 2010; Hall \& Pain, 2006; Merrifield, 2011; Brenner \& Schmid, 2011; Schmid 2012, 2006; Brenner 2013). Como lo explican Soja \& Kanai (2007):

(...) el urbanismo como modo de vida, una vez limitado a la ciudad central histórica, se ha ido extendiendo hacia el exterior, creando densidades urbanas y nuevas ciudades "periféricas" y "de borde" en lo que antes eran franjas suburbanas y campos o sitios rurales. En algunas áreas, la urbanización se ha expandido a escalas regionales aún más grandes, creando enormes galaxias urbanas con tamaños de población y grado de policentrismo más allá de lo imaginado hace solo unas pocas décadas (...). [E]n algunos casos las ciudades-región se están uniendo a aglomeraciones aún mayores en un proceso que podría ser llamado "urbanización regional extendida". (p. 59)

Merrifield (2011) caracteriza la transformación en términos muy similares:

La urbanización del mundo es una especie de exteriorización del interior, y a la vez la interiorización del exterior: lo urbano se abre hacia el campo del mismo modo en que el campo se vuelve a abrir hacia la ciudad (...). Sin embargo, los puntos de quiebre entre estos dos mundos no están definidos por cualquier división urbanorural sencilla, ni por norte-sur; en cambio, los centros y las periferias son inmanentes dentro de la acumulación de capital en sí (...). Los lugares rurales, absorbidos y destruidos por unidades más vastas, se han convertido en una parte integral de la producción posindustrial y la especulación financiera, tragados por un "tejido urbano" que extiende continuamente sus fronteras y que corroe sin cesar el residuo de la vida agraria, engulléndolo todo a su paso para aumentar la plusvalía y acumulación de capital. (pp. 468, 469)

Kingsley Davis (1955, p. 437) reconoció explícitamente estas poderosas tendencias hacia la urbanización extendida y "reducción de la ruralidad" ya en la década de 1950, pero continuó conceptualizando la "ciudad" (o, eventualmente, la región metropolitana) como la unidad básica dentro de la cual se contenían las dinámicas demográficas de la urbanización, tanto analítica como geográficamente. Al mismo tiempo, tal como la mayoría de los científicos sociales de posguerra, Davis persistió en la clasificación de la esfera incipiente "fuera" o "más allá" de la ciudad en expansión usando la noción tradicional de lo rural, a pesar de que claramente reconocía que su coherencia y su carácter independiente estaban comprometidos de manera constante a través de la metropolización, suburbanización, formación de megalópolis y diversas formas de descentralización industrial, residencial y de infraestructura. Sorprendentemente, las declaraciones contemporáneas de una edad urbana replican esta oposición metodológica acogiendo el marco conceptual idéntico e imaginario geográfico en el que Davis se había basado -en particular, el supuesto básico de que el espacio de asentamiento global puede y debe ser claramente dividido en recipientes urbanos o rurales-. Sobre esta base, la tesis plantea un cambio inevitable de la población, tanto en términos relativos como absolutos, para el componente urbano de esta dualidad. 
Mientras que el discurso de la era urbana por lo general se presenta como un conjunto de afirmaciones empíricas respecto a tendencias demográficas y sociales, estas últimas se presuponen sobre un marco teórico y cartográfico subyacente cuyas principales suposiciones, una vez excavadas y escrutadas, son profundamente problemáticas. La figura 4 presenta una visión de los elementos clave dentro de este marco y su relación con las tendencias metodológicas más amplias en las ciencias sociales urbanas de los siglos XIX y Xx. (figura 4)

FIGURA 4 | Arquitectura conceptual de la tesis de la era urbana

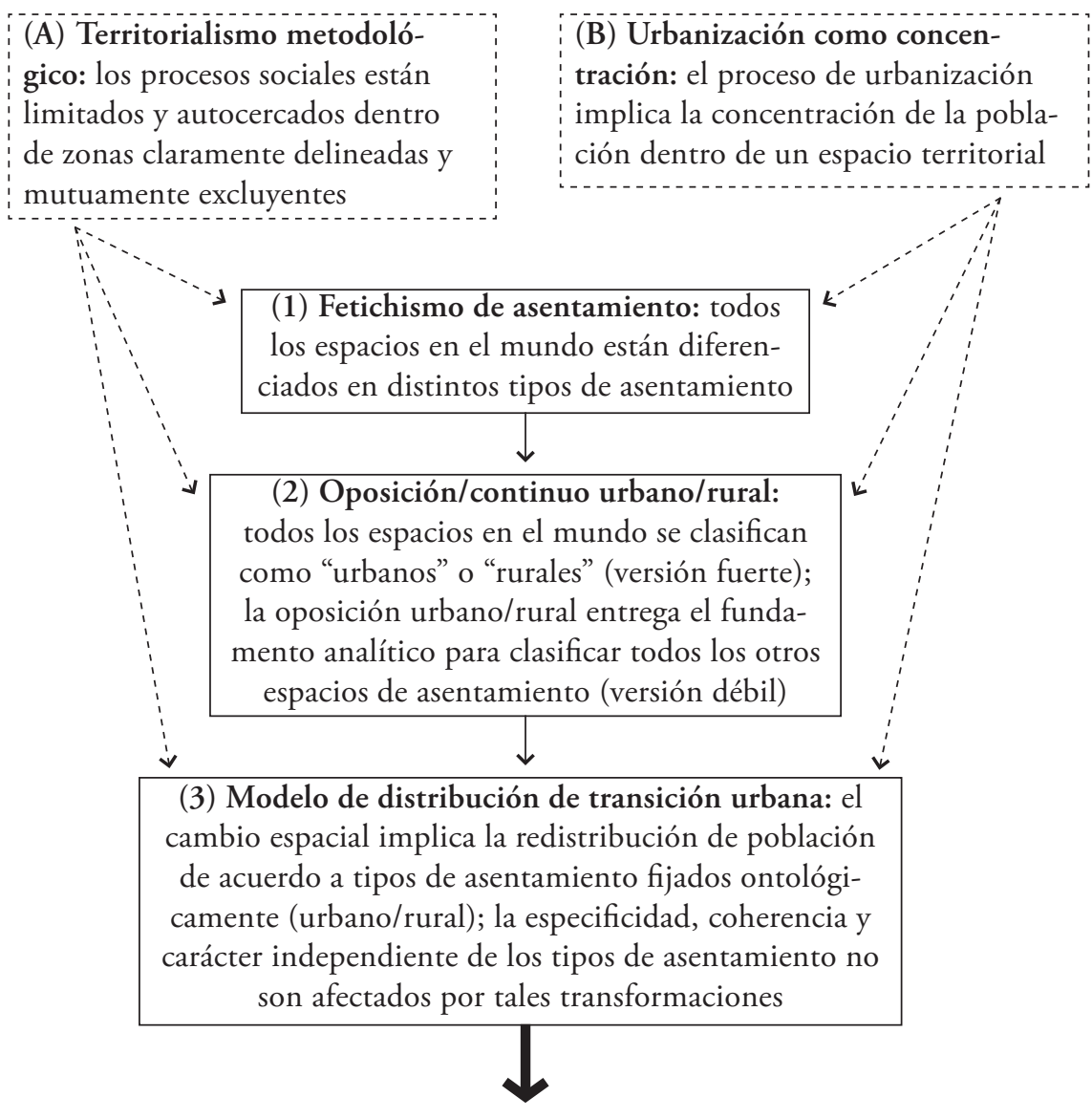

LA TESIS DE LA ERA URBANA

En el 2008 el mundo logra un hito invisible pero trascendental. Por primera vez en la historia, más de la mitad de la población humana, 3.3 billones de personas, estarán viviendo en áreas urbanas (UNFPA, 2007: 1).

FUENTE ELABORACIÓN PROPIA

NOTA LAS LÍNEAS DISCONTINUAS Y LAS FLECHAS INDICAN UNA INFLUENCIA CONTRIBUYENTE; LAS LÍNEAS EN NEGRITA Y LAS FLECHAS INDICAN UN SUPUESTO TEÓRICO CENTRAL 
Como indica la figura 4, el núcleo intelectual de la tesis de la era urbana (1) es el supuesto metodológicamente territorialista de que el mundo se divide en tipos de asentamientos independientes, cuya clasificación facilita la comprensión de las principales tendencias demográficas y socioeconómicas. Sobre esta base, (2) la oposición urbano/rural es presentada como la base analítica para este tipo de clasificaciones, un supuesto que a su vez depende de la afirmación, por lo general no cuestionada, (B) según la cual ciertas condiciones sociales únicas que no existen en otros lugares se producen dentro de las ciudades y aglomeraciones. En la mayor parte del discurso de la era urbana, esta oposición se entiende en términos de suma cero: todo espacio de asentamiento debe ser clasificado como urbano o rural; la extensión de lo urbano, por lo tanto, implica la disminución de lo rural. A pesar de que esta conceptualización se remonta más comúnmente a la influyente teoría de urbanismo de Wirth (1969 [1937]), su análisis estaba de hecho -como se señaló antes- reflexivamente en sintonía con el papel de la urbanización en la intensificación de las interdependencias interespaciales y la reorganización territorial en todo el mundo. Ocasionalmente, los argumentos de la era urbana se basan en versiones más débiles de este supuesto, utilizando la oposición urbano/rural para demarcar un continuo de tipos de asentamiento en lugar de ser presentados como una elección ontológica (véase UN-DESA, 1969, p. 66). Pero incluso dentro de este enfoque más diferenciado, la oposición urbano/rural sirve como un ancla epistemológica para el ejercicio de clasificación de los supuestamente distintos tipos de espacios de asentamiento. Ya sea que se lo presente como un dualismo o como un continuo, este modelo engendra (3) una noción distributiva de transición urbana en el que se dice que el cambio socioespacial se produce a través de la redistribución de las poblaciones de zonas rurales a las urbanas. La posibilidad de que estos espacios de asentamiento puedan ser deconstruidos o transformados, en el proceso de reestructuración socioespacial queda excluida de la consideración por decreto.

En todas las versiones contemporáneas de la tesis de la era urbana se presupone alguna versión de esta constelación de supuestos, pero se exhiben de forma particularmente clara en la figura 5, extraída de la edición más reciente de la publicación de World Urbanization Prospects de las Naciones Unidas (UN-DESA-PD, 2012).

Estas visualizaciones del conjunto de datos urbanos más reciente de la onU encarnan, paradigmáticamente, el marco teórico y cartográfico asociado a la noción de una era urbana. La parte inferior de la figura 5 representa la evolución geográfica de la población mundial a través de la aplicación de una clasificación urbano/rural binaria de cada región del mundo en 1950, 2011 y 2050, respectivamente. En este sentido, la distribución de la población mundial puede cambiar, como el contenido de un reloj de arena, pero los recipientes en los que se ubican las poblaciones siguen siendo ontológicamente fijos. La oposición urbano/rural se concibe, entonces, como una característica constante e inmutable del espacio de asentamiento global, que se aplica universalmente en las formaciones sociales y períodos de tiempo. La parte superior de la figura 5 espacializa este conjunto de supuestos en un mapa del mundo que muestra los niveles de urbanización en todos los territorios nacionales. A pesar de que sus datos están actualizados y su técnica de visualización ligeramente modificada, este mapa es analíticamente idéntico a aquel producido por los investigadores 
de la ONu en 1969 (véase la figura 3; un-DESA, 1969). Al igual que en la década de 1960, la urbanización sigue siendo representada como una propiedad de territorios nacionales, nuevamente codificados gráficamente en función de sus respectivos niveles porcentuales de población urbana (no rural). Mientras que la parte superior de la figura 5 también muestra las ubicaciones y niveles de población de algunas de las ciudades más grandes del mundo, su principal objetivo es clasificar los territorios nacionales a través de la cartografía dualista urbano/rural descrita anteriormente. ${ }^{4}$

FIGURA 5 | La división ontológica del espacio de asentamiento en zonas urbanas y rurales en recientes datos e imágenes de la onU
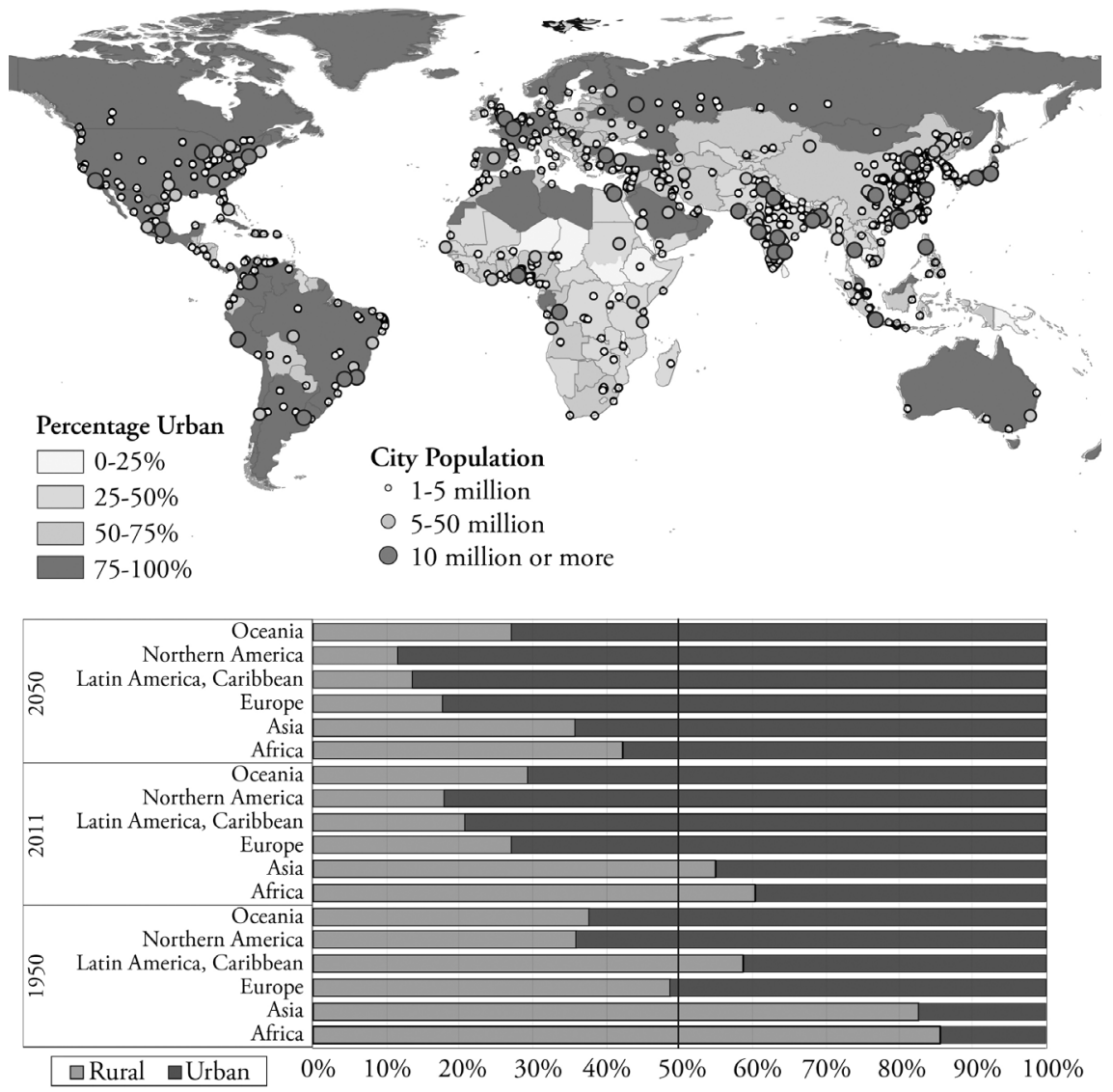

FUENTE REDISEÑADO DESDE UN-DESA-PD, 2OI 2: HTTP://ESA.UN.ORG/UNPD/WUP/ANALYTICALFIGURES/FIG_2.HTM Y HTTP://ESA.UN.ORG/UNPD/WUP/MAPS/MAPS_URBAN_2OII.HTM, ACCEDIDO EL I 4 DE JUNIO DE 2012

Recientes visualizaciones formalmente idénticas de los datos de población urbana de la oNU incluyen un enfoque cronológico producido por Unicef (http://www.unicef.org/sowc2012/ urbanmap/) y una asignación de código de colores de un periodista de The Guardian (http://image. guardian.co.uk/sys-files/Guardian/documents/2007/06/27/URBAN_WORLD_2806.pdf). 
En la década de 1950, el dualismo urbano/rural ofrecía un punto de referencia conceptual para que los demógrafos de orientación empírica de la ONU entendieran los diferenciales observados en las tasas de mortalidad infantil y tasas de fecundidad entre poblaciones en diferentes tipos de asentamiento (Champion \& Hugo, 2004, p. 5). Hoy, sin embargo, esta dualidad, y el concepto más amplio de era urbana a la que se ha unido, han llegado a servir a un propósito académico y sociocultural más amplio. La sensación de que las ciudades están cambiando y creciendo con rapidez e intensidad sin precedentes; que mayor parte del territorio habitable del mundo se está volviendo "urbano"; que el antiguo campo está siendo erosionado o degradado; y que estas tendencias representan algo así como un hito en el desarrollo humano a nivel mundial, son generalizaciones que, no obstante simplistas, parecen ofrecer un "mapa cognitivo" viable (Jameson, 1988) para navegar por un paisaje socioespacial de rápida reestructuración en todo el mundo, definido este por la turbulencia, la incertidumbre y las descontroladas tendencias de crisis, a la vez sociales, espaciales y ambientales. En consecuencia, la popularidad de la tesis de la era urbana, ya sea en el discurso académico, político, corporativo o en la vida cotidiana, parece estar conectada a las formas en que sugiere la denominación e interpretación de las transformaciones de la organización socioespacial urbana en todo el mundo.

Nuestra afirmación, sin embargo, es que este mapa cognitivo confunde mucho más de lo que aclara con respecto a los procesos contemporáneos de urbanización. Particularmente a la luz de las amplias y disruptivas transformaciones socioespaciales delineadas por Soja y Kanai (2007) y por Merrifield (2011) en los pasajes citados anteriormente, la cartografía teórica asociada con la noción de que la era urbana funciona como una concepción caótica en el sentido técnico preciso definido por Sayer (1992): "divide lo indivisible y/o agrupa aquello sin relación y accesorio, por lo tanto 'reparte' el objeto de estudio con poca o ninguna consideración por su estructura y forma” (p. 138).

En primer lugar, la tesis de la era urbana divide lo indivisible en la medida en que considera fundamentalmente distintas las zonas urbanas y las rurales, ignorando así la huella generalizada de los procesos de urbanización en espacios de asentamiento que, ya sea por criterios de tamańo de población, clasificación administrativa u otros, se catalogan oficialmente como rurales. La sugerencia de una brecha analítica u ontológica entre estos tipos de espacios supuestamente distintos impide la exploración de su estructura a partir de procesos político-económicos, incluyendo la acumulación de capital, la regulación estatal, la privatización de los recursos comunes (incluyendo el suelo), la financiación, la migración y la degradación/ transformación socioambiental. Una vez que se lleva a cabo este tipo de análisis, el uso de la denominación "rural" se vuelve muy problemático (Halfacree, 2004), al menos como una categoría de análisis científico social. Cada vez más, el proceso de urbanización se ha convertido en una condición global en lugar de simplemente un "modo de vida" limitado a ciertos tipos de espacio de asentamiento en comparación con otros (Lefebvre 2003 [1970]; Merrifield, 2011; Soja, 2010). Esta formación planetaria emergente de la urbanización es profundamente desigual y variada, y los patrones emergentes y las vías de diferenciación socioespacial de este tejido urbano 
en todo el mundo sin duda requieren de una investigación sostenida en distintas escalas geográficas (Schmid, 2012, 2006). Sin embargo, debido a su dependencia de una dualidad urbano/rural obsoleta hace ya mucho, la noción de una era urbana es un instrumento aproximado para este fin.

En segundo lugar, la tesis de la era urbana agrupa aquello no relacionado y accesorio debido a su especificación inadecuada respecto de qué fenómenos específicos están destinados a ser contenidos dentro de cada término de la dualidad urbano/rural. Tal como se utiliza en el discurso de la era urbana, ambas categorías son generalizadas hasta el punto de la falta de sentido; cada una se refiere a condiciones extremadamente heterogéneas dentro y entre los territorios nacionales. En su mayor parte, la noción de lo rural utilizada en el discurso de la era urbana es simplemente una "caja negra": se refiere a las zonas residuales de asentamiento que son supuestamente "no urbanas", pero esto se hace sin especificar cuáles son las características que estos espacios pueden compartir en distintos contextos, ya sea en términos de tamańo de la población, densidad o composición, uso del suelo, mercados de trabajo u otros indicadores. Más problemático aún, al contrario de esta caja negra de lo rural, es que la noción de lo urbano utilizada en el discurso de la era urbana está radicalmente sobreespecificada. El concepto de lo urbano asociado con la tesis de la era urbana se utiliza para referirse a tantas condiciones distintas de población, infraestructura y organización administrativa que pierde toda coherencia analítica. Mientras que la noción de una era urbana generalmente pretende implicar un cambio en todo el mundo hacia una condición urbana mundial, su base probatoria abarca un amplio espectro de condiciones de asentamientos, que van desde ciudades pequeńas y medianas a centros regionales, núcleos metropolitanos, grandes regiones-ciudad y megaciudades en expansión con poblaciones superiores a 10 millones (Montgomery, 2010). Sin embargo, "hay poco en común entre las pequeñas ciudades basadas en el comercio en áreas con economías estancadas en (por ejemplo) Argentina, China e India y Buenos Aires, Shanghai y Delhi" (Satterthwaite, 2010, p. 96). Dada la heterogeneidad de barrido de las configuraciones de asentamiento y procesos transformadores dentro del concepto de era urbana, es muy dudoso que se le pueda atribuir un contenido teórico significativo.

Volvemos así a la orientación reflexiva teórica hacia la cuestión urbana destacada por Wirth y Castells hace muchas décadas. Como ambos autores insistieron, sin especificación teórica reflexiva, el concepto de lo urbano seguirá siendo una abstracción vacía desprovista de contenido analítico de fondo y, por lo tanto, una herramienta imprecisa para descifrar o dar luces respecto de la naturaleza de las condiciones, procesos y transformaciones a las que se aplica. A menos que los defensores de la tesis de la era urbana expliquen qué fenómenos específicos-socioespaciales, demográficos, administrativos u otros- unifican aquellas zonas de asentamiento aparentemente no relacionadas, o no esencialmente conectadas, que obtienen con su categorización por lo general vaga del espacio de asentamiento, entonces esta condición metodológica crucial no se cumple; el término seguirá siendo no más que una abstracción vacía. 


\section{Conclusión: hacia una investigación de urbanización planetaria}

Incluso basados en concepciones caóticas, los entendimientos hegemónicos de los principales procesos sociales pueden tener impactos de amplio alcance, ya que median el discurso experto y popular, la representación, imaginación y la práctica en relación con asuntos de gran impacto para la organización de las relaciones políticoeconómicas. En consecuencia, como argumenta Wachsmuth (2014), la dimensión ideológica de la urbanización requiere un análisis sostenido y la deconstrucción de los teóricos urbanos clave, especialmente en condiciones en las que las formaciones arraigadas de organización socioespacial se reorganizan radicalmente para producir nuevos paisajes de urbanización cuyos límites permanecen borrosos, volátiles y confusos y, por lo tanto, están particularmente sujetos a formas antojadizas de narración, representación y visualización (véase también Goonewardena, 2005).

Sería sumamente valioso, entonces, realizar un seguimiento de las formas en que se ha difundido y naturalizado la noción de una era urbana entre los actores relevantes e instituciones de todo el sistema urbano mundial, y examinar así cómo ha influenciado las políticas relacionadas con la condición urbana global. ${ }^{5}$ Por ejemplo, Satterthwaite (2010, pp. 95-96) sugiere que los datos sesgados asociados con la tesis de la era urbana han tenido ramificaciones particularmente problemáticas en los debates sobre políticas relacionadas con la pobreza urbana, la salud pública y las emisiones de efecto invernadero en el sur del mundo. También es posible imaginar fácilmente una serie de áreas de políticas relacionadas, incluyendo los mercados de trabajo, la vivienda, la educación, el transporte, el desarrollo de infraestructura y el suministro de energía, en que los preceptos teóricos asociados con esta tesis (y, de hecho, con cualquier otro modelo que defina rígidamente una división urbano/ rural estricta) han engendrado comprensiones erróneas, distorsionadas y confusas de las fuerzas de múltiples escalas que configuran los patrones de urbanización contemporánea de todo el mundo (McGee, 2008).

Un análisis más amplio de las efectividades prácticas de la tesis de la era urbana sería de considerable interés y relevancia en cualquier escala espacial, sobre todo para aquellas comprometidas con la promoción de formas viables de una urbanización socialmente más justa y ecológica en el norte y el sur. Por el momento, sin embargo, tal esfuerzo recién está comenzando a emprenderse en relación con lugares específicos y regímenes de políticas en los que la tesis de la era urbana ha llamado la atención explícita entre los responsables de las políticas, por ejemplo, debido a la intensa publicidad local generada a través de las iniciativas de conferencias de viaje de LSE-Deutsche Bank en megaciudades del sur (Anand \& Rademacher, 2011).

¿Se puede construir un mapa cognitivo alternativo de formaciones emergentes de urbanización que sustituya las múltiples limitaciones y puntos ciegos asociados con el discurso de la era urbana y otras ideologías contemporáneas de la urbanización? La urgencia de esta tarea es mitigada por el empirismo arraigado que

Para un ejemplo brillante de cómo realizar un seguimiento de este proceso de transferencia de políticas interespaciales y mutación de escalas y territorios en el contexto de las tendencias contemporáneas de neoliberalización, consultar Theodore y Peck (2012); Peck y Theodore (2010). 
domina gran parte de la ciencia social urbana contemporánea y el discurso político, lo que lleva a los investigadores a hacer hincapié en las investigaciones concretas y visualizaciones asociadas en lugar de interrogar los supuestos conceptuales y los marcos cartográficos subyacentes en torno a los que se organizan. Este problema ha sido reconocido desde hace tiempo por los teóricos espaciales radicales, pero sigue obstaculizando la innovación teórica en los estudios urbanos de principios del siglo XXI, debido a la persistencia de ideologías espaciales firmemente arraigadas que tratan lo urbano como una formación predeterminada y evidente que requiere ser investigada o manipulada. Sin embargo, como Ananya Roy (2009) ha argumentado en una poderosa crítica a la hegemonía de las teorías urbanas euroamericanas: "es el momento de hacer estallar las geografías teóricas abiertas, para producir una nueva serie de conceptos en el crisol de un nuevo repertorio de las ciudades” (p. 820). En una línea similar, Jennifer Robinson (2011) ha requerido recientemente una "matriz rica y fragmentada de las conversaciones de ciudades en curso en todo el mundo" (p. 19), que servirá para desestabilizar certezas teóricas definidas parroquialmente. Apoyamos firmemente que estos llamados reemplacen epistemologías urbanas heredadas, pero que a la vez busquen conectarse con ellas, en particular para una nueva conceptualización de los procesos de urbanización, tanto dentro como fuera de los espacios de asentamiento demarcados como "ciudades".

Si bien aquí no es posible elaborar en detalle nuestro enfoque alternativo para tal esfuerzo, se concluye con la descripción de un conjunto de orientaciones epistemológicas que se derivan de la crítica anterior de la tesis de la era urbana. Nuestro propio trabajo actual sobre urbanización planetaria está basado en estos preceptos, pero creemos que podrían informar de manera productiva una variedad de compromisos heterodoxos con la cuestión urbana en condiciones de principios del siglo XXI.

- Lo urbano y la urbanización son categorías teóricas. Lo urbano no es una realidad, condición o forma predeterminada y evidente por sí misma; su especificidad solo puede ser definida en términos teóricos, a través de una interpretación de sus propiedades, expresiones o dinámicas fundamentales. Es esencial, por lo tanto, que los debates del siglo xxi sobre cuestiones urbanas acojan de manera reflexiva la necesidad de abstracciones conceptuales relacionadas con la cambiante forma y geografía de los procesos de urbanización. Sin este trabajo recursivo de la teoría, el campo de los estudios urbanos estará mal equipado para descifrar la naturaleza y las implicaciones de las transformaciones complejas, multiescala que se aspira a entender. El discurso de la era urbana representa una expresión particularmente grave de la última tendencia y de los riesgos intelectuales y cartográficos asociados.

- Lo urbano no es una forma universal, sino un proceso histórico. En contraste con los conceptos heredados de lo urbano como una unidad por definición fija o estática, se debe entender que sus significados y expresiones evolucionan históricamente en relación con patrones más amplios y vías de desarrollo capitalista mundial. Concebida de esta manera, la urbanización es un proceso de transformación socioespacial continua, una "agitación" implacable de los tipos de asentamiento y morfologías que comprenden los territorios enteros y no 
solo "puntos" o "zonas" aisladas dentro de ellos. Como insistió Lefebvre (2003 [1970]), el estudio de las formas urbanas debe ser sustituido por la investigación de los procesos de urbanización en todas las escalas espaciales.

- Las dimensiones socioespaciales de la urbanización son polimórficas, variables y dinámicas. Gran parte de los estudios urbanos del siglo xx acogieron una cartografía metodológicamente territorialista en la que lo urbano era tratado como un tipo de asentamiento relativamente delimitado y supuestamente independiente de las presuntas zonas no urbanas situadas más allá o fuera de la urbe. El discurso de la era urbana representa solo el ejemplo más reciente e influyente de esta tendencia metodológica arraigada hace bastante tiempo. Tales concepciones territorialistas de ciudad basadas en asentamiento tuvieron una base en la morfología de la urbanización industrial metropolitana durante los siglos XIX y xx, pero incluso entonces representaban parcial y unilateralmente una urbanización de paisaje polimorfo, variable y de dinámica incesante. Sin embargo, dada la diferenciación acelerada de los paisajes urbanos en todo el mundo desde la década de 1980 (Brenner \& Schmid, 2011; Schmid, 2012), es evidente que las nociones basadas en los asentamientos de la condición urbana se han vuelto obsoletas. Lo urbano no puede entenderse plausiblemente como un sitio de las relaciones sociales delimitado y cerrado que ha de contrastarse con las zonas o condiciones no urbanas. Es hora, por lo tanto, de hacer explotar nuestras suposiciones heredadas en cuanto a las morfologías, territorializaciones y dinámicas socioespaciales de la condición urbana.

- La urbanización implica concentración y extensión. Una vez que la urbanización es vista como un proceso que transforma diversas zonas del mundo, se debe reemplazar otra tendencia metodológicamente arraigada; más específicamente, el enfoque exclusivo o principal de los investigadores urbanos sobre aglomeraciones, zonas densamente pobladas (ciudades, regiones metropolitanas, regiones megaciudad y así sucesivamente) en las que se agrupan los sistemas de población y las actividades económicas y de infraestructura. En este modelo, que no solo respalda la tesis de la era urbana sino que parte de la teoría urbana del siglo xx, el ámbito no urbano se interpreta simplemente como un campo vacío, como un exterior indeterminado que sirve para demarcar la condición urbana de su supuesto "otro" exurbano o rural. Sin embargo, a lo largo de la historia del capitalismo moderno, este terreno nunca ha estado ni vacío ni desconectado del proceso de aglomeración; de hecho, ha evolucionado de forma dinámica a través de una compleja red en crecimiento de conexiones económicas, sociales y ecológicas hacia los núcleos de la concentración urbana de todas las zonas de la economía mundial. Aunque en gran parte ignoradas o relegadas a un segundo plano analítico por los teóricos urbanos, dichas transformaciones - materializadas en los circuitos densamente intrincados de mano de obra, formas culturales, energía, materias primas y nutrientes- simultáneamente irradian hacia el exterior de la zona inmediata de aglomeración y vuelven a colapsar a medida que se desarrolla el proceso de urbanización. Dentro de este campo del desarrollo urbano y equipamientos de infraestructura cada vez más extendido 
en todo el mundo, las aglomeraciones se forman, se expanden, se contraen y se transforman constantemente, pero siempre a través de redes de relaciones densas hacia otros lugares, cuyos patrones históricos y vías de desarrollo están a su vez mediados cada vez más directamente a través de sus modos de conexión/ desconexión de las zonas hegemónicas de concentración urbana. Estas observaciones sugieren un punto de partida metodológico para un enfoque radicalmente reinventado de la urbanización (capitalista): el desarrollo del concepto de urbanización extendida para complementar y reposicionar el énfasis en los procesos de aglomeración que ha sustentado la investigación urbana desde hace mucho tiempo. ${ }^{6}$ Se cree que tal concepto tiene importantes implicaciones para segmentar en períodos la urbanización desde la aparición del capitalismo industrial, y también tiene un potencial considerable para guiar la investigación sobre la condición urbana de principios del siglo XxI.

- La urbanización se ha convertido en un fenómeno planetario. Hoy en día, la urbanización es un proceso que afecta a todo el territorio del mundo y no solamente a partes aisladas. Lo urbano representa un tejido desigual cada vez mayor en todo el planeta, donde se entrelazan las relaciones socioculturales y políticoeconómicas del capitalismo. Esta situación de la urbanización planetaria significa que incluso las disposiciones socioespaciales, y redes de infraestructura que se encuentran más allá de los núcleos tradicionales de la ciudad, las regiones metropolitanas, las periferias urbanas y zonas periurbanas, se han convertido en parte integrante de la condición urbana en todo el mundo. ${ }^{7} \mathrm{Al}$ mismo tiempo, la oposición urbano-rural, respaldada durante mucho tiempo por la epistemología de conceptos urbanos, ha sido profundamente desestabilizada, tanto en las ciencias sociales como en la práctica de planificación y en la vida cotidiana. En resumen, ya no hay ningún exterior del mundo urbano; lo no urbano se ha interiorizado en gran medida dentro de un proceso planetario, pero desigual de urbanización. En estas condiciones, el binarismo urbano-rural es una base cada vez más confusa para descifrar las morfologías, contornos y dinámicas de la reestructuración socioespacial en el capitalismo de principios del siglo XXI.

- La urbanización produce nuevas diferenciaciones constantemente. La urbanización es un proceso de transformación constante y conduce continuamente a la producción de nuevas configuraciones y constelaciones urbanas. Las zonas de la urbanización y, de modo más general, la condición urbana, no deberían ser

6 El término "urbanización extendida” fue acuñado por Monte-Mór (2005, 2004), y recientemente fue utilizado por Soja (2010). Al hacer uso de su vocabulario, nuestra conceptualización es específica al marco teórico desarrollado aquí y en otros medios para la investigación de la problemática de la urbanización planetaria. Para una descripción más detallada, consultar Brenner y Schmid (2012).

7 Hemos comenzado a explorar esta propuesta a través de una serie de investigaciones de diversos "territorios extremos" de urbanización -la Amazonía, el Ártico, los Himalayas, el desierto de Gobi, el océano Pacífico, el desierto del Sahara, Siberia y la atmósfera- en Urban Theory LabGSD. Se espera que este trabajo, que combina economía política espacializada, cartografía clave y análisis geocomparativo, pueda iluminar las transformaciones en curso de estas zonas remotas de la economía mundial y forjar nuevas categorías teóricas para el estudio de la urbanización. 
tratadas como homogéneas, ni en la era contemporánea ni aplicadas a períodos históricos anteriores. Más bien, los procesos de urbanización producen una amplia gama de condiciones socioespaciales mundiales que requieren un análisis y teorización contextualmente específicos. Como se discutió anteriormente, la tesis de la era urbana envuelve cada polo de la división urbano/rural dentro de una caja negra analítica. Se centra en la distribución de la población entre las dos cajas en vez de explorar sus contenidos sustantivos, las condiciones de emergencia o las vías de desarrollo. Así, cada término dentro de la dualidad no es más que una abstracción vacía, ya que ninguno está adecuadamente en sintonía con los patrones masivos de diferenciación que caracterizan los procesos de urbanización. En consecuencia, y con bastante urgencia, es necesario abrir las cajas negras y explorar sus contenidos. El universo urbano planetario de hoy revela una amplia variedad de situaciones diferenciadas y polarizadas, condiciones y contestaciones que requieren una investigación contextualmente específica, pero teóricamente reflexiva.

- Se necesita un nuevo vocabulario de urbanización. Los vocabularios analíticos y métodos cartográficos heredados no captan adecuadamente la naturaleza cambiante de los procesos de urbanización, y sus expresiones intensamente heterogéneas, en el mundo contemporáneo. Los patrones emergentes y las vías de urbanización planetaria, por tanto, requieren el desarrollo de nuevos enfoques, métodos y conceptos analíticos, incluyendo los experimentales y especulativos, así como nuevas visualizaciones de las condiciones sociometabólicas y socioespaciales en evolución. En resumen, se requiere un nuevo léxico de los procesos de urbanización y formas de diferenciación territorial con el fin de captar las geografías inestables y en constante cambio del capitalismo de principios del siglo xxI. ${ }^{8}$

Las maniobras de análisis que aquí se proponen son, sin duda, discutibles y seguramente requieren elaboración adicional, más detallada. Aunque muchos lectores pueden oponerse a las consecuencias metodológicas ciertamente radicales derivadas de nuestra crítica del discurso de la era urbana, esperamos que nuestras propuestas ayuden a estimular un debate mayor con respecto a la mejor manera de conceptualizar la condición urbana global contemporánea. Desde nuestro punto de vista, tal debate ha caducado no solo entre urbanistas, sino que entre todos los académicos, profesionales y activistas enfocados en entender y, por lo tanto, dar nueva forma al tejido socioespacial de nuestra existencia planetaria compartida. ${ }^{9}$

Hay diversos proyectos para el desarrollo de tal vocabulario, basados en los conceptos, métodos y estrategias cartográficas desarrollados en investigaciones anteriores del tejido urbano de Suiza, producidos por ETH Studio Basel (Diener et al., 2006). Más recientemente, el proyecto de investigación "Patrones y vías de la urbanización planetaria" organizado por ETH Future Cities Laboratory Singapore, compara los procesos de urbanización en nueve extensas áreas urbanas (Tokio, Hong Kong/Shenzhen, Singapur, Calcuta, Estanbul, Lagos, París, Ciudad de México y Los Ángeles). Al explorar la amplia gama de procesos contemporáneos de urbanización, este proyecto pretende desestabilizar conceptos de lo urbano y expandir nuestro imaginario sobre él (consultar Schmid, 2012).

9 Para una lectura complementaria, ver: Brenner, N. (2016) La explosión de lo urbano. Santiago: Ediciones ARQ. 


\section{Agradecimientos}

En relación con los comentarios críticos y sugerencias clave de este artículo, estamos muy agradecidos de Nikos Katsikis, Jenny Robinson, Nathan y David Sayre Wachsmuth, así como de los revisores de IJURR. Obviamente, asumimos plena responsabilidad de los puntos ciegos pendientes, errores u omisiones. Agradecemos la ayuda en la investigación de Sky Milner, Hallie Chen, Travis Bost y Héctor TarridoPicart de la Escuela de Diseño de Harvard, y el generoso apoyo a la investigación del Centro Weatherhead para Asuntos Internacionales de la Universidad de Harvard.

Nota: esta tribuna es una traducción del artículo original publicado en inglés: Brenner, N. and Schmid, C. (2014), The 'Urban Age' in Question. Int J Urban Reg Res, 38: 731-755. doi:10.1111/1468-2427.12115. (C) 2013 Urban Research Publications Limited. Published by John Wiley \& Sons Ltd. 9600 Garsington Road, Oxford OX42DQ, uk and 350 Main St, Malden, ma 02148, usA.

\section{Referencias bibliográficas}

Anand, N. \& Rademacher, A. (2011). Housing in the urban age: Inequality and aspiration in Mumbai. Antipode, 43 (5), 1748-1772. doi: 10.1111/j.1467-8330.2011.00887.x

Angel, S. (2011). Making room for a planet of cities. Cambridge, MA: Policy Focus Report. Lincoln Institute of Land Policy.

Ash, C., Jasny, B., Robert, L., Stone, R. \& Sugden, A. (2008). Reimagining cities. Science, 319 (5.864), 739. doi: 10.1126/science.319.5864.739

Berger, A. (2006), Drosscape: Wasting Land in Urban America. New York: Princeton Architectural Press.

Berry, B. (1961). City size distributions and economic development. Economic Development and Cultural Change, 9 (4), 573-588. En http://isites.harvard.edu/fs/docs/icb. topic1050993.files/Berry\%201961.pdf

Bloom, D., Canning, D., Fink, G., Khanna, T. \& Salyer, P. (2010). Urban settlement: data, measures, trends. En J. Beall, B. Guha-Khasnobis and R. Kanbur (Eds.), Urbanization and development. Oxford: Oxford University Press.

Bocquier, P. (2004). World urbanization prospects: an alternative to the UN model of projection compatible with urban transition theory. Document de Travail DIAL, Unité de Recherche CIPRÉ, Paris.

Brenner, N. (2004). New State Spaces. New York: Oxford University Press.

Brenner, N. (2012). Louis Wirth's radiant urbanism: a contribution to the investigation of world urbanization. Working paper, Urban Theory Lab, Harvard GSD.

Brenner, N. (2013). Theses on urbanization, Public Culture, 25 (1), 85-114. doi: $10.1215 / 08992363-1890477$

Brenner, N. \& Katsikis, N. (2013). Is the world urban? Towards a critique of geospatial ideology. Moscow: Strelka Press. 
Brenner, N. \& Schmid, C. (2011). Planetary urbanization. In M. Gandy (Ed.), Urban Constellations. Berlin: Jovis.

Brenner, N. \& Schmid, C. (2012). Towards a theory of extended urbanization. Working Paper, Urban Theory Lab, Harvard GSD у етн Zurich.

Brockerhoff, M. (2000). An urbanizing world. Population Bulletin, 55 (3), 3-43. En http://bit. ly/1URdN9H

Burdett, R. \& Rode, P. (2006). The urban age project. En R. Burdett \& D. Sudjic (Eds.), The endless city. London: Phaidon.

Burdett, R. \& Rode, P. (2010). Living in the urban age. En R. Burdett and D. Sudjic (Eds.), Living in the endless city. London: Phaidon.

Burdett, R. \& Sudjic, D. (Eds.). (2006). The endless city. London: Phaidon.

Burdett, R. \& Sudjic, D. (Eds.). (2010). Living in the endless city. London: Phaidon.

Castells, M. (1976). Is there an urban sociology? En C. Pickvance (Ed.), Urban sociology: critical essays. London: Methuen.

Castells, M. (1977 [1972]). The urban question: a Marxist approach. Cambridge, MA: MIT Press.

Castells, M. (2002) Preface. En P. Evans (Ed.), Livable cities? Berkeley, CA: University of California Press.

Champion, T. (2004). Lest we re-invent the wheel: lessons from previous experience. En T. Champion \& G. Hugo (Eds.), New forms of urbanization. London: Ashgate.

Champion, T. \& Hugo, G. (2004). Introduction. En T. Champion \& G. Hugo (Eds.), New forms of urbanization. London: Ashgate.

Cohen, B. (2004). Urban growth in developing countries: A review of current trends and a caution regarding existing forecasts. World Development, 32 (1), 23-51. http://dx.doi. org/10.1016/j.worlddev.2003.04.008

Cronon, W. (1991). Nature's Metropolis: Chicago and the Great West. New York: Norton.

Davis, K. (1945). The world demographic transition. Annals of the American Academy of Political and Social Science, 237 (1), 1-11. doi: 10.1177/000271624523700102

Davis, K. (1955). The origins and growth of urbanization in the world. American Journal of Sociology, 60 (5), 429-437.

Davis, K. (1959). The world's metropolitan areas. Berkeley y Los Angeles: International Urban Research, Institute for International Studies / University of California Press.

Davis, K. (1965). The urbanization of the human population. Scientific American, 213 (3), 40-53.

Davis, K. (1969). World urbanization 1950-1970. Volume I: Basic data for cities, countries and regions. Population Monograph Series No. 4. Berkeley, CA: Institute of International Studies, University of California.

Davis, K. (1972). World urbanization 1950-1970. Volume II: Analysis of trends, relationships and development. Population Monograph Series No. 9. Berkeley, CA: Institute of International Studies, University of California.

Davis, K. \& Hertz Golden, H. (1954). Urbanization and the development of pre-industrial areas. Economic Development and Cultural Change, 3 (1), 6-26.

Davis, M. (2006). Planet of slums. London: Verso.

Diener, R., Herzog, J., Meili, M., de Meuron, P. \&. Schmid, C. (2006). Switzerland: an urban portrait. Vols. 1-4. ETH Studio Basel. Zurich: Birkhäuser. 
Elden, S. (2010). Land, terrain, territory. Progress in Human Geography, 34 (6), 799-817. doi: $10.1177 / 0309132510362603$

Gans, H. (2009). Some problems of and futures for urban sociology. City and Community, 8 (3), 211-219. doi: 10.1111/j.1540-6040.2009.01286.x

Gibbs, J. \& Davis, K. (1958). Conventional versus metropolitan data in the international study of urbanization. American Sociological Review, 23 (5), 504-514.

Gibbs, J. \& Schnore, L. (1960). Metropolitan growth: an international study. American Journal of Sociology, 66 (2), 160-170. doi: 10.1086/222845

Gleeson, B. (2012). Critical commentary. The Urban Age: Paradox and prospect. Urban Studies, 49 (5), 931-943. doi: 10.1177/0042098011435846

Glissant, E. (Ed.). (1985). The urban explosion. The UNESCO Courier, 38, 24-30. En http:// unesdoc.unesco.org/images/0006/000634/063438eo.pdf

Goonewardena, K. (2005). The urban sensorium: Space, ideology, and the aestheticization of politics. Antipode, 37 (1), 46-71. doi: 10.1111/j.0066-4812.2005.00473.x

Halfacree, K. (2004). Rethinking 'rurality'. En T. Champion \& G. Hugo (Eds.), New forms of urbanization London: Ashgate.

Hall, P. \& Pain, K. (2006) The polycentric metropolis. London: Earthscan.

Hoyt, H. (1966 [1962]). World urbanization. Reprinted in According to Hoyt: 50 years of Homer Hoyt. Washington, DC: Autor.

Hugo, G. \& Champion, T. (2004). Conclusions and recommendations. En T. Champion and G. Hugo (eds.), New forms of urbanization. London: Ashgate.

Jameson, F. (1988). Cognitive mapping. En L. Grossberg \& C. Nelson (Eds.), Marxism and the interpretation of culture. Chicago: University of Illinois Press.

Jessop, B., Brenner, N. \& Jones, M. (2008). Theorizing socio-spatial relations. Environment and Planning D: Society and Space, 26(3), 389-401. doi: 10.1068/d9107

Koolhaas, R. (2000). Mutations: Harvard Project on the City. Barcelona: Actar.

Lefebvre, H. (2003 [1970]). The Urban Revolution. Trad. por Robert Bonnono. Minneapolis, MN: University of Minnesota Press.

Madden, D. (2012). City becoming world: Nancy, Lefebvre and the global-urban imagination. Environment and Planning D: Society and Space, 30 (5), 772-787. doi: 10.1068/d17310

Marx, K. \& Engels, F. (2000 [1848]). The communist manifesto. En D. McLellan (Ed.), Karl Marx: selected writings ( $2^{\text {nd }}$ ed.). London: Oxford University Press.

McGee, T. (2008). Managing the rural-urban transformation in East Asia in the $21^{\text {st }}$ century. Sustainability Science, 3 (1), 155-167. doi: 10.1007/s11625-007-0040-y

McKinsey Global Institute (2011). Urban world: mapping the economic power of cities. London: McKinsey \& Company.

Merrifield, A. (2011). The right to the city and beyond. City, 15 (3-4), 468-476. doi: 10.1080/13604813.2011.595116

Monte-Mór, R. L. M. (2004). Modernities in the Jungle: Extended Urbanization in the Brazilian Amazon. Ph.D. Thesis, Department of Urban Planning, University of California Los Angeles.

Monte-Mór, R. L. M. (2005). What is the urban in the contemporary world? Cadernos de Saúde Pública, 21 (3), 942-948. En http://dx.doi.org/10.1590/S0102-311X2005000300030 
Montgomery, M. (2010). The demography of the urban transition: What we know and don't know. En G. Martine, G. McGranahan, M. Montgomery \& R. Fernandez-Castilla (Eds.), The new global frontier. London: Earthscan.

Montgomery, M. \& Balk, D. (2011). The urban transition in developing countries. En E. Birch \& S. Wachter (Eds.), Global urbanization. Philadelphia: University of Pennsylvania Press.

Peck, J. \& Theodore, N. (2010). Recombinant workfare, across the Americas: transnationalizing "fast" social policy. Geoforum, 41 (2), 195-208. http://dx.doi.org/10.1016/j. geoforum.2010.01.001

Potere, D. \& Schneider, A. (2007). A critical look at representations of urban areas in global maps. GeoJournal, 69 (1), 55-80. doi: 10.1007/s10708-007-9102-z

Potere, D., Schneider, A., Angel, S. \& Civco, D. (2009). Mapping urban areas on a global scale: Which of the eight maps now available is more accurate? International Journal of Remote Sensing, 30 (24), 6531-6558. doi: 10.1080/01431160903121134

Robinson, J. (2011). Cities in a world of cities: The comparative gesture. International Journal of Urban and Regional Research, 53 (1), 1-23. doi: 10.1111/j.1468-2427.2010.00982.x

Roy, A. (2009). The $21^{\text {st }}$ century metropolis: New geographies of theory. Regional Studies, 43 (6), 819-830. doi: 10.1080/00343400701809665

Satterthwaite, D. (2007). The transition to a predominantly urban world and its underpinnings. Human Settlements Discussion Paper, International Institute for Environment and Development (IIED), London.

Satterthwaite, D. (2010). Urban myths and the mis-use of data that underpin them. En J. Beall, B. Guha-Khasnobis \& R. Kanbur (Eds.), Urbanization and development. Oxford: Oxford University Press.

Sayer, A. (1984). Defining the urban. GeoJournal, 9(3), 279-285.

Sayer, A. (1992) Method in Social Science ( $2^{\text {nd }}$ ed.). New York: Routledge.

Schmid, C. (2006). Theory. En R. Diener, J. Herzog, M. Meili, P. de Meuron \& C. Schmid, Switzerland: An urban portrait, vol. 1, 163-221, етн Studio. Basel, Switzerland: Birkhäuser Verlag.

Schmid, C. (2012). Patterns and pathways of global urbanization: towards comparative analysis. En J. Acebillo (Ed.), Globalization of urbanity (pp. 51-77). Barcelona: Università della Svizzera Italiana / Actar.

Schnore, L. (1964). Urbanization and economic development: The demographic contribution. American Journal of Economics and Sociology, 23 (1), 37-48. doi: 10.1111/j.15367150.1964.tb00931.x

Scruton, P. (2007). The new urban world. The Guardian (27 junio). En http://image.guardian. co.uk/sys-files/Guardian/documents/2007/06/27/URBAN_WORLD_2806.pdf (acceso 15 junio 2012).

Soja, E. (2000). Postmetropolis. Cambridge, MA: Blackwell.

Soja, E. (2010). Regional urbanization and the end of the metropolis era. En G. Bridge \& S. Watson (Eds.), The new Blackwell companion to the city. Cambridge, MA: Blackwell.

Soja, E. \& Kanai, M. (2007). The urbanization of the world. En R. Burdett \& D. Sudjic (Eds.), The endless city. London: Phaidon.

Taylor, P. J. (1994). The state as container: territoriality in the modern world-system. Progress in Human Geography, 18 (2), 151-162. doi: 10.1002/9780470755686.ch6 
Taylor, P. J. (2002). A brief guide to quantitative data collection at GaWC, 1997-2001. Globalization and World Cities Research Network, Loughborough University. En http://www.lboro.ac.uk/gawc/guide.html (acceso 30 mayo 2012).

Theodore, N. \& Peck, J. (2012). Framing neoliberal urbanism: translating 'common sense' urban policy across the OECD zone. European Urban and Regional Studies, 19(1), 2041. doi: $10.1177 / 0969776411428500$

Uchida, H. \& Nelson, A. (2010). Agglomeration index: towards a new measure of urban concentration. En J. Beall, B. Guha-Khasnobis \& R. Kanbur (Eds.), Urbanization and development. Oxford: Oxford University Press.

United Nations Department of Economic and Social Affairs (UN-DESA). (1969). Growth of the world's urban and rural population, 1920-2000. Population Studies No. 44. New York: United Nations.

United Nations Department of Economic and Social Affairs, Population Division (UN-DeSAPD). (2002). World urbanization prospects, the 2001 revision. New York: United Nations.

United Nations Department of Economic and Social Affairs, Population Division (UN-DESAPD). (2012). World urbanization prospects, the 2011 revision. New York: United Nations.

United Nations Human Settlement Programme (un-Habitat) (1996) An urbanizing world: Global Report on human settlements, 1996. Oxford University Press for Un-Habitat, Oxford.

United Nations Human Settlement Programme (un-Habitat). (2007). The state of the world's cities Report 2006/2007-30 years of shaping the Habitat agenda. London: Earthscan for un-Habitat.

United Nations Human Settlement Programme (un-Habitat). (2011). The state of the world's cities Report 2010/2011 - Cities for all: bridging the urban divide. London: Earthscan for UN-Habitat.

UNICEF (2012). An urban world: urban population map. En http://www.unicef.org/sowc2012/ urbanmap/ (acceso 15 junio 2012).

United Nations Population Fund (UNFPA). (2007). State of world population 2007: unleashing the potential of urban growth. United Nations Population Fund (New York). En http:// www.unfpa.org/swp/2007/english/introduction.html (acceso 14 junio 2012).

Wachsmuth, D. (2014). City as ideology: Reconciling the explosion of the city form with the tenacity of the city concept. Environment and Planning D: Society and Space, 32 (1), 75-90. doi: 10.1068/d21911

Weber, A. F. (1899). The growth of cities in the nineteenth century: a study in statistics. New York: Macmillan.

Weissmann, E. (1965). The urban crisis in the world. Urban Affairs Quarterly, 1 (1), 65-82. doi: $10.1177 / 107808746500100105$

Wirth, L. (1969 [1937]). Urbanism as a way of life. En R. Sennett (Ed.), Classic essays on the culture of cities. Engelwood Cliffs, NJ: Prentice Hall. 
RESEÑAS 